Review began 10/21/2021 Review ended 10/27/2021 Published 10/30/2021

(c) Copyright 2021

Philips et al. This is an open access article distributed under the terms of the Creative Commons Attribution License CC-BY 4.0. which permits unrestricted use, distribution, and reproduction in any medium, provided the original author and source are credited.

\title{
Critical Updates on Chronic Hepatitis B Virus Infection in 2021
}

\author{
Cyriac A. Philips ${ }^{1}$, Rizwan Ahamed ${ }^{2}$, Jinsha K. Abduljaleel ${ }^{2}$, Sasidharan Rajesh ${ }^{3}$, Philip Augustine ${ }^{2}$ \\ 1. Clinical and Translational Hepatology, The Liver Institute, Rajagiri Hospital, Aluva, IND 2. Gastroenterology and \\ Advanced Gastrointestinal Endoscopy, Center of Excellence in Gastrointestinal Sciences, Rajagiri Hospital, Aluva, IND \\ 3. Diagnostic and Interventional Radiology, Center of Excellence in Gastrointestinal Sciences, Rajagiri Hospital, Aluva, \\ IND
}

Corresponding author: Cyriac A. Philips, abbyphilips@gmail.com

\begin{abstract}
Chronic hepatitis B virus (HBV) infection is a global healthcare burden in the form of chronic liver disease, cirrhosis, liver failure and liver cancer. There is no definite cure for the virus and even though extensive vaccination programs have reduced the burden of liver disease in the future population, treatment options to eradicate the virus from the host are still lacking. In this review, we discuss in detail current updates on the structure and applied biology of the virus in the host, examine updates to current treatment and explore novel and state-of-the-art therapeutics in the pipeline for management of chronic HBV. Furthermore, we also specifically review clinical updates on HBV-related acute on chronic liver failure (ACLF). Current treatments for chronic HBV infection have seen important updates in the form of considerations for treating patients in the immune tolerant phase and some clarity on end points for treatment and decisions on finite therapy with nucleos(t)ide inhibitors. Ongoing cutting-edge research on HBV biology has helped us identify novel target areas in the life cycle of the virus for application of new therapeutics. Due to improvements in the area of genomics, the hope for therapeutic vaccines, vector-based treatments and focused management aimed at targeting host integration of the virus and thereby a total cure could become a reality in the near future. Newer clinical prognostic tools have improved our understanding of timing of specific treatment options for the catastrophic syndrome of ACLF secondary to reactivation of HBV. In this review, we discuss in detail pertinent updates regarding virus biology and novel therapeutic targets with special focus on the appraisal of prognostic scores and treatment options in HBV-related ACLF.
\end{abstract}

Categories: Internal Medicine, Gastroenterology, Infectious Disease

Keywords: acute hepatitis, liver failure, hepatocellular carcinoma, chronic hepatitis, aclf, acute liver failure, antiviral, portal hypertension, cirrhosis, hbv

\section{Introduction And Background}

The prevalence of hepatitis B virus (HBV) surface antigen positivity among the general population differs according to geographical region, which also dictates possible routes of transmission. In low prevalence $(<2 \%)$ regions such as North America and Western Europe, age at infection in early adulthood and route of transmission is mostly sexual and percutaneous. In regions of moderate prevalence (2-8\%), age at infection in childhood and perinatal transmission is the most common mode of spread. Previously, age-dependent phases of HBV were described as immunotolerant phase (high replication, low-inflammation), immunoactive phase, inactive carrier state (low replication levels with normal/nearly normal serum aminotransferase levels) and reactivation. Nonetheless, these have been renamed recently as HBV envelope antigen (HBeAg)-positive infection, HBeAg-positive hepatitis and HBeAg-negative infection and HBeAgnegative hepatitis. Progression to cirrhosis in HBeAg-positive patients occurs at a rate of 2 to $5.5 \%$ per year increasing from 8 to $20 \%$ in five years. Inactive carriers who have normal aminotransferase levels and HBV DNA levels $<2,000 \mathrm{IU} / \mathrm{ml}$ experience disease regression at the rate of 0.5 to $2 \%$ per year. HBeAg-negative hepatitis, or the reactivation phase, represents a progressive stage of chronic HBV. Anti-HBe (antibody to eantigen)-positive patients experience rapid progression to cirrhosis at an annual rate of 8 to $20 \%$. Patients with cirrhosis progress to advanced liver disease and hepatic failure at a rate of $16 \%$ over five years [1-4]. Chronic HBV infection remains a huge burden on the patients, their family and the healthcare system the world over, mostly in the Asia-Pacific region. There have been rapid developments toward a functional cure of HBV infection, with novel compounds currently in various study phases. Our current understanding of pathogenesis, immunology and clinical outcomes of HBV infection has seen vast updates over the last decade. In this narrative review, we provide in-depth discussions on the current understanding of biology and immuno-pathogenesis; variants and genotypes of HBV infection and extrapolate the same toward discussing novel therapies. We also explore current treatment options and discuss with clarity the guideline recommendations on HBV treatments, specifically updates on the special clinical condition of acute on chronic liver failure (ACLF) related to HBV infection.

\section{Review}

\section{Updates on HBV-related applied biology}


HBV infection is a dynamic disease that encompasses biochemical, histological and clinical changes that occur over time, depending on the mode of acquisition, host and environmental factors. Within the host, HBV can exist in three forms, the infectious virion (Dane particle) and non-infectious particles that include enveloped nucleocapsids containing immature DNA/RNA, subviral particles (spheres, filaments lacking nucleocapsid proteins) and naked nucleocapsids $[5,6]$. According to the Baltimore Classification, a system utilized to group viruses taking into consideration both transcription and replication, on the basis of manner of messenger RNA (mRNA) synthesis, HBV belongs to Group VII which includes double-stranded DNA viruses with an RNA intermediate. HBV is a partially double-stranded hepadnavirus with a size of $42 \mathrm{~nm}$ containing a relaxed-circular DNA (rcDNA) genome with complete minus and incomplete plus strands. It has a host-derived outer surface lipid coat containing surface antigen which consists of large (L-), middle (M-) and small (S-HBsAg) and an inner core protein called the hepatitis B core antigen (HBcAg). The pre-S1 domain of the L-HBs plays a key role in viral envelopment and drives infectivity [7].

The viral genome encodes four overlapping open reading frames (ORFs): $\mathrm{C}$ (pre-core and core regions), $\mathrm{P}, \mathrm{S}$ (pre-S1, pre-S2, S regions), and X (from which functional viral proteins are produced). The core antigen (nucleocapsid) protein, $\mathrm{HBcAg}$; and the 'e' antigen (HBeAg) and 22-kDa pre-core protein (p22cr) are produced from ORF-C core and pre-core regions respectively. The polymerase protein (Pol) encoded from ORF-P is made of terminal domain with functions of encapsidation and initiation of minus strand synthesis; the reverse transcriptase domian (RT) which catalyzes genome synthesis; and the ribonuclease (H) domain which degrades pregenomic RNA and facilitates replication. HBV X antigen protein (HBxAg) is encoded by ORF-X and has multiple functions that support various stages of viral replication including signal transduction, DNA repair, activation of transcription pathways and inhibition of protein degradation along with participation in the oncogenic potential of HBV [8-11]. In the S-domain, the intermolecular disulfide bonds contribute to the structural stability of spherical virions and promote high resistance of HBV to inactivation by dehydration and heat stress $[12,13]$. Other important functional elements include direct repeats (DR1 and DR2) required for strand-specific synthesis of DNA during replication and enhancer elements (En1 and En2) which promote liver-specific expression of HBV gene products. Apart from this, a glucocorticoid-responsive element (GRE) sequence within the S-domain, a post-transcriptional regulatory element also exists. This region controls gene transcription and protein activation either by reversible events such as posttranslational modifications of phosphorylation or sequestration; and via irreversible events such as proteolysis. The GRE overlaps En1 and the polyadenylation signal (which makes transcribed RNA more stable, prevents degradation and allows the mature messenger RNA molecule to be exported from the nucleus and translated into a protein by ribosomes in the cytoplasm) within the core gene [14]. To summarize, apart from the major structural proteins, additional functional components in HBV have been demonstrated to enhance replication, promote liver-specific expression of viral proteins, prevent viral protein degradation and improve structural stability during cellular entry.

Updates on Viral Entry

The mode of entry and HBV replication steps within the hepatocyte has been extensively updated in the last decade. The virus attaches to the host cell surface (basolateral membrane of hepatocyte) through initial lowaffinity binding on highly sulfated-heparan sulfate proteoglycans (HSPG) such as hepatotropic glypican-5 followed by high-affinity binding on target receptor. This binding to the HSPGs is mediated by electrostatic interactions between the negatively charged HSPG and two positively charged residues of the S-domain [15]. Initial studies showed that heparin, a glycosaminoglycan, interfered with HBV attachment. The higher the sulfation, the stronger the inhibition - lesser sulfated glycosaminoglycans such as chondroitin sulfate were less effective in blocking HBV entry. Thereafter the region between amino acids at position 2 and 47 of the pre-S1 of the HBV acts as receptor binder and attaches to the liver cell entry receptor. The latter was identified as the sodium taurocholate co-transporting peptide (NTCP, coded by the SLC10A1 gene; functions to uptake conjugated bile acids into hepatocytes). It is interesting to note that NTCP expression is rapidly lost after isolation of primary human hepatocytes and is absent in poorly differentiated hepatocellular carcinomas (HCC). Thus, malignant hepatoma cells and primary hepatocytes do not support and are not susceptible to infection with HBV (lack of efficient cell culture system permissive for viral infection and replication). Nonetheless, recently, human pluripotent stem cells transformed to hepatocyte-like cells (HLC) were found capable of expressing hepatocyte markers and host factors needed for the development of HBV infection [16]. Virus internalization into the hepatocyte cytoplasm occurs through the process of endocytosis in which the viral material to be internalized is surrounded by an area of host cell plasma membrane, which then buds off inside the cell to form a vesicle containing the ingested viral material. HBV infection was low in cell lines with overexpressed NTCP. This meant that the co-factors for internalization and infection were important for viral infection. It was identified that the receptor tyrosine kinase, also known as the epidermal growth factor receptor (EGFR), through interaction with the NTCP triggers the internalization and endocytosis process mediated by the caveolae-1/lipid-raft and possibly clathrin, leads to the formation of endosomes in the cytoplasm [17,18]. The host-cell protein, the calcium-dependent cell adhesion E cadherin was shown to play a central role in HBV entry. This protein binds to the glycosylated NTCP and promotes relocation to the basolateral membrane (cell polarization). On a different note, the cell-polarization limits entry of hepatitis $C$ virus through tight junctions that restrict viral access to receptor binding [19]. 
There are three different types of endosomes: early endosomes, late endosomes, and recycling endosomes, differentiated by their morphology, the time taken for the endocytosed material to reach them, and by markers such as Ras superfamily of G proteins called Rabs. Once endocytic vesicles uncoat, they fuse with early endosomes (via Rab5A) which then mature into late endosomes before fusing with lysosomes (via Rab7A) [20]. In the HBV internalization cycle, the EGFR activation triggers a time-dependent relocalization of HBV pre-S1 to early and late endosomes and to lysosomes in concert with EGFR transport. However, blockade of EGFR-downstream signaling proteins including mitogen-activated protein kinase (MAPK), phosphoinositide 3-kinase (PI3K), and signal transducer and activator of transcription (STAT), does not have a significant effect in reducing HBV infection. Interestingly, efficiency of EGFR endocytosis and HBV entry were reduced when there was a deleterious mutation in EGFR or genetic knockdown of endocytosis adaptor molecules. In this regard, it was demonstrated that the suppression of EGFR ubiquitination by site-directed mutagenesis or knockdown of the EGFR-sorting molecules [signal-transducing adaptor molecule (STAM) and lysosomal protein transmembrane $4 \beta$ (LAPTM4B)] ameliorated EGFR transport to the late endosome which was shown to be critical for efficient HBV infection. Another novel finding is that the hepatocyte NTCP undergoes extensive oligomerization in the presence of HBV preS1. Oligomerization refers to the interaction of more than one polypeptide chain, which results in the formation of the quaternary structure, generally considered to be the highest level of organization within the protein structural hierarchy. The drug troglitazone (but not pioglitazone) blocked internalization of HBV preS1 and its receptor, NTCP by preventing oligomerization. This work represented the importance of small molecule and peptide-based therapy in prevention of HBV infection [21,22]. Clathrin-mediated virus entry also plays a role in HBV internalization, in which the interaction with protein adapter-2 (AP-2) facilitates infection. Silibinin, a known inhibitor of clathrin-mediated endocytosis was shown to reduce HBV virus entry of HepG2-NTCP cell line [23]. Internalized virus escapes from the endocytic pathway once signaling that support fusion is activated. The crucial aspect in fusion mechanism is dependent on the $\mathrm{pH}$. Some of the identified (but not confirmed) fusogenic domains include the C-terminal half of the pre-S2 region, the N-terminal of the Sregion, pre-S1 region and the $\mathrm{N}$-terminal of pre-S1 region [24,25]. To summarize, HBV entry into hepatocytes is not only governed by attachment of pre-S1 to the NTCP receptor, but also initial priming through low-affinity binding with heparan sulfate proteins on hepatocyte, internalization via the tyrosine receptor kinase EGFR, oligomerization to stabilize viral structure orchestrated by multiple other small molecules such as host cell calcium-dependent E cadherin, clathrin and adapter proteins that all form novel drug targets. For example, bafilomycin A1, an inhibitor of vacuolar enzymes responsible for acidification of pH gradient within endosomes inhibited HBV in duck hepatocytes and ameliorated HBV in human cell lines. Further, silencing of small molecules (Rabs) that transport plasma membranes to endosomes also significantly reduced HBV infection. Depending on the structure and biology of HBV, various entry inhibitors have been tested in pre-clinical studies. These include: a. Attachment inhibitors targeting S-,M-,L-HBs (heparin and suramin) or pre-S1 (proanthocyanidins); b. HSPGs (synthetic anti-lipopolysaccharide peptides); c. Substrate inhibitors of NTCP that target NTCP [taurocholic acid and derivatives such as ursodeoxycholic acid (UDCA), tauro-UDCA and glyco-UDCA, irbesartan]; d. Those targeting NTCP + Niemann-Pick C1-Like 1 (NPC1L1) protein (ezetimibe); e. Direct inhibitors of NTCP that interfere (cyclosporine A, vanitaracin A); f. Those that mildly or do not interfere (myrcludex-B, SCY450, SCY995 and Evans blue) with bile acid uptake and; g. Those which directly regulate NTCP expression (Ro41-5253, retinoic acid receptor antagonist) [26,27].

Updates on Nuclear Transport, Assembly and Release

After escape from the late endosome, the viral particles traverse the cytoplasm towards the host cell nucleus. As previously stated, the membrane fusion leads to direct release of nucleocapsids into the cytoplasm. A conserved membrane-permeable peptide within the surface protein of HBV was recently identified, of the pre-S2 domain, called the translocation motif (TLM). The TLM promotes delivery of proteins and nucleic acids into cells and tissues. Surface exposure of TLM peptides on the HBV surface protein due to proteolytic processing leads to fusion of peptides to HBc protein enabling formation of fully assembled capsids [28-32]. These viral capsids then translocate (via microtubule mediated transport) as complete 'virus' across cytoplasm towards the nucleus. The microtubule transport assembly is dependent on tubulin distribution and linkage of capsids to the dynein-motor-complex (cytoskeletal motor proteins that move along microtubules). Nocodazole is a drug that can depolymerize microtubules and thus block viral nucleocapsids from reaching the host cell nucleus, preventing formation of covalently closed circular DNA (cccDNA) that defines the HBV life cycle. Nonetheless, microtubule destabilizing drugs are associated with severe side effects and cannot be utilized in clinical setting [33-36]. The viral nucleocapsids undergo disassembly at the host-cell nuclear pore complex where the HBV rcDNA is converted to cccDNA which serves as a template for transcription of viral RNAs (pre-genomic and sub-genomic RNA). HBV pre-genomic RNA contains a stem loop called epsilon which is essential for RNA generation and packaging into viral capsids. It is through interaction with the Zinc finger antiviral protein (ZAP), interferon treatment destabilizes RNA generation and reduces viral replication. Similar to ZAP, recent studies have identified that multiple other small molecules and cellular factors interact with the HBV RNA to promote or suppress degradation and affect viral replication. These include cytidine deaminase, splicing factors, small ribonucleoprotein, RNA-binding motif protein and peroxiredoxins, which also act as small molecular targets for HVB therapy [37-40].

Updates on Viral Transcription and cccDNA 
Within the cytoplasm, along with viral polymerase, pre-genomic RNA is encapsidated by HBV core protein to form a viral capsid. Inside the viral capsid, pre-genomic RNA undergoes reverse transcription to generate single-stranded negative-strand DNA (immature nucleocapsids, within infected cells), further followed by generation of partially double-stranded DNA (mature nucleocapsids, in released viral particles) yielding viral rcDNA. These capsids containing rcDNA are either transported back into the nucleus to increase the cccDNA pool or enveloped and released as progeny virions. HBsAg production is predominantly from cccDNA in younger HBeAg-positive patients. Hypo-phosphorylation of capsid proteins produces regular virions while hyper-phosphorylation produces empty virions [41-44]. The reverse transcription also produces aberrant by-products called HBV double-stranded linear DNA that are either released as defective virions or integrate with the host genome. This aberrant integration fails to transcribe pre-genomic RNA (no replicative power), but could still act as a template for generation of HBsAg. This happens in older chronic HBV patients who are HBeAg negative. Currently approved medications for HBV such as interferon- $\alpha$ and nucleos(t)ide reverse transcriptase inhibitors (NAs) reduce viral replication and slow disease progression, but do not cure chronic HBV infection. This is because these agents do not have any effect on persistent HBV cccDNA, since cccDNA formation is not only dependent on the viral DNA polymerase but also the host DNA polymerase(s). In this regard, it was shown that the anti-retroviral host factor SAMHD1 binds to singlestranded virus DNA, acting as a scaffolding protein to facilitate formation of cccDNA through relaxed circular DNA repair processes [45-47]. The HBx protein was demonstrated to activate HBV transcription through recruitment onto cccDNA. HBx also counteracts host restriction mechanisms of cccDNA transcription. Recently, the smallest known proteins with prolyl isomerase activity, which catalyze the cistrans isomerization of proline peptide bonds, Parvulin 14 and Parvulin 17, were discovered to bind to $\mathrm{HBx}$ and cccDNA and promote HBV replication in an HBx-dependent manner. Thus, HBx itself and HBx-involved protein-protein interactions form novel molecular targets for therapeutic development against HBV [48-50]. A recent study found that the Smc5/6 of the structural maintenance of chromosomes family suppresses HBV replication. The drug nitazoxanide was found to block the inhibitor of Smc5/6 (damage specific DNA binding protein 1 or DDB1 binding to HBx protein) and promote suppression of replication [51]. Each infected hepatocyte contains one to 10 cccDNA copies with a half-life of 9.2 months in NA-treated chronic HBV patients. To clear cccDNA from infected cells, apart from direct targeting of cccDNA, two other steps are imperative. First, viral replication and cccDNA replenishment must be completely blocked, and, second, exhaustion of the pool of pre-existing cccDNA within a specified time frame. In the presence of potent suppression of viral replication with an NA addition of small interfering RNA or capsid inhibitor may help clear cccDNA completely [52-54].

With respect to cccDNA clearance, two pathobiological processes are pertinent. One, hepatocyte proliferation itself contributes to reduction in load of cccDNA within infected hepatocytes. In patients with advanced fibrosis or cirrhosis, the hepatocyte replicative senescence adds to the burden of cccDNA formation. Destruction of infected hepatocytes in the presence of potent replication suppression will help reduce cccDNA formation - a therapeutic approach that would require combination of multi-targeted treatment strategies. The cccDNA removal also occurs via non-cytolytic clearance of infected hepatocytes in the presence of antiviral cytokines, specifically interferon- $\alpha$. It was shown that higher levels of interferon- $\alpha$ were associated with improved cccDNA clearance through triggering of non-cytolytic degradation of cccDNA from infected hepatocytes through induction of the nuclear deaminase A3A or A3B. However, such high doses in a clinical scenario can lead to adverse events and hence are impractical. Recently, the PASylation (addition of polypeptide comprising Proline, Alanine and Serine to increase plasma half-life) of interferon- $\alpha$ was found to improve antiviral effect without additional toxicity [55-59]. Figure 1 summarizes an updated schematic of the HBV life cycle and pertinent therapeutic targets. 


\section{Cureus}

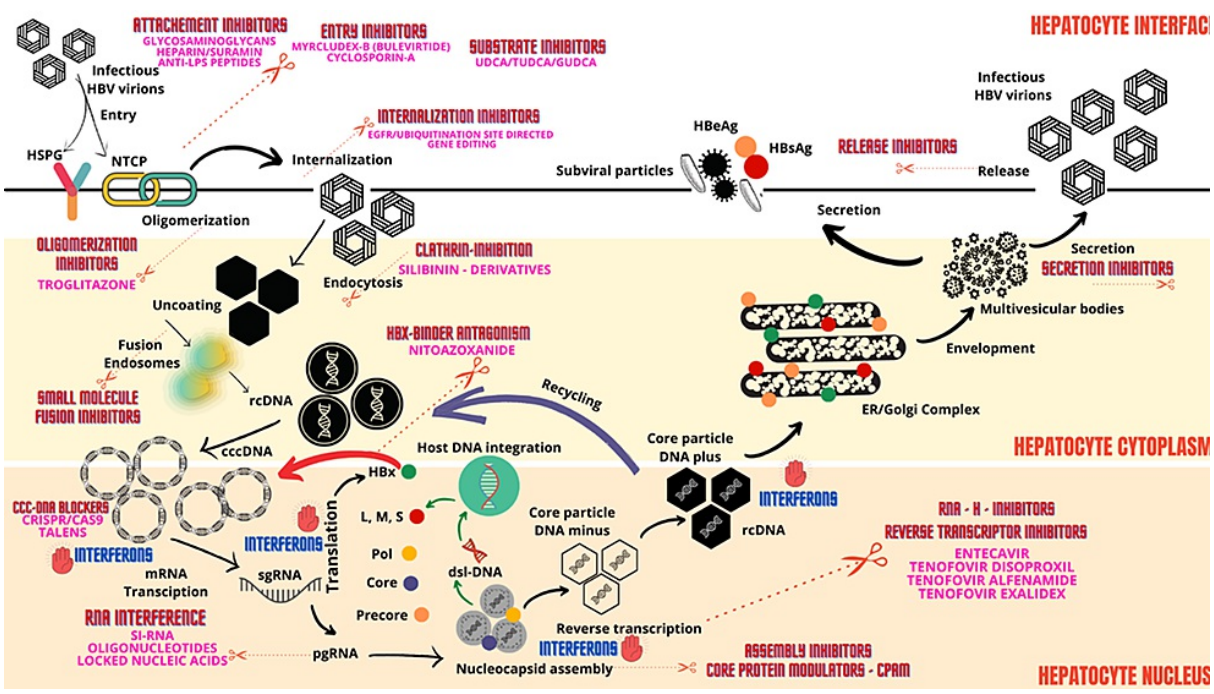

FIGURE 1: Schematic representation of hepatitis B virus (HBV) life cycle, pertinent steps of host infection and targets for new antiviral therapies.

HSPG - heparin sulfate proteoglycans, NTCP - Sodium taurocholate co-transporting polypeptide, LPS lipopolysaccharide, UDCA - ursodeoxycholic acid, TUDCA - tauro-UDCA, GUDCA - glyco-UDCA, HBeAg - HBV envelope antigen, $\mathrm{HBsAg}$ - HBV surface antigen, $\mathrm{ER}$ - endoplasmic reticulum, $\mathrm{RNA}-\mathrm{H}$ - ribonuclease $\mathrm{H}$, rcDNArelaxed circular DNA, cccDNA - covalently closed circular DNA, mRNA - messenger RNA, siRNA - small interfering RNA, pgRNA - pregenomic RNA, sgRNA - subgenomic RNA, CPAM - core protein allosteric modulator, Pol - polymerase, L - large HBsAg, S - small HBsAg, M - medium HBsAg

Updates on immunopathogenesis, genetic variants and applied biology

Host immune response against HBV infection includes innate immunity and adaptive immunity. The former includes downstream responses that are activated by pattern recognition receptor (PRR), natural killer (NK) cells, NK-T cells, and monocytes and macrophages; while the latter includes cluster of differentiation (CD)4 + T lymphocytes, CD8 + T lymphocytes, and B lymphocytes. In chronic HBV infection, the virus limits and evades antiviral effects of the innate immune and adaptive immune system through various mechanisms, resulting in continuous replication associated with dysfunction of various immune cells. HBeAg is immunomodulatory and is involved in antigen presentation and recognition by CD4+T cells. In $\mathrm{HBeAg}$ negative HBV infection (associated with pre-core stop codon mutation), there is rapid progression, cirrhosis and liver cancer development due to amelioration of host innate immune functions. Similarly, the HBV core promoter mutation in enhancer II which results in enhanced viral replication is accompanied by a reduction or loss of HBeAg leading to fulminant or progressive chronic hepatitis. The HBsAg mutant - defect in S region to arginine at amino acid position 145 and loss of group-specific antigenic determinant a (target of vaccine response) - escapes immune surveillance and infection even in the presence of antibodies to surface antigen and also development of occult HBsAg negative HBV infection. Vaccine-escape mutations occurred in particular when lamivudine (currently not utilized) was used in the long term [60-64]. The size of exposure or inoculum determines HBV persistence and clearance. Low-dose inoculum leads to a massive spread of the virus in all of the hepatocytes and viral persistence; whereas high-dose inoculum showed a limited spread of the virus to hepatocytes and rapid viral clearance. This phenomenon depends on the synchronized effector activity of CD4+ and CD8+ T cells. Exhaustion and depletion of CD4+ T cells in limited exposure infection along with synchronized influx of HBV-specific CD8+ T cells in the liver promotes viral persistence. In high viral load, interferons- $\alpha / \beta$ suppress viral replication through transcriptional and posttranscriptional modification. In early infection and low viral load, HBV utilizes host interferon response to promote viral persistence via stimulation of enhancer I in the genome which interacts with STAT3 and hepatocyte nuclear factor $3 \gamma$ (HNF3 $\gamma$ ). Innate immune activation functions through PRRs recognizing pathogen-associated molecular patterns (PAMPs). These include: a. Toll-like (TLRs; TLR2 activation promotes pro-inflammatory cascade for viral clearance, TLR4 activation through HBsAg related dendritic cell, soluble CD14 dependent cytotoxic T cell mechanism) receptors; b. Retinoic acid-inducible gene I (RIG)like (dual antiviral effect on pre-genomic RNA through type III interferon induction and HBV polymerase interaction) receptor; c. Nucleotide-binding oligomerization domain-containing protein (NOD)-like, C-type lectin receptors and d. DNA-sensing (cytosolic cGAS recognize HBV DNA, suppress interferon suppressing regulatory factor 3 , promote viral persistence) receptors.

Some preclinical studies have shown that, in early HBV infection, PRR-mediated innate immune responses are not activated - the stealth virus phenomenon where the virus interferes with innate signaling pathways to attenuate intrinsic antiviral immune responses [65-67]. HBsAg and HBeAg, in a dose-dependent manner, 
via interference with c-Jun N-terminal kinases (JNK) activation, inhibits expression of TLR2 mediated IL-12 and tumor necrosis factor- $\alpha$ (TNF- $\alpha$ ) production in monocytes and macrophages. HBV also suppressed nuclear factor kappa B (NF-KB), extracellular signal-regulated kinase (ERK)1/2, blocked myeloid differentiation primary response 88 (MYD88) protein expression and inhibited type 1 interferon induction (via HBxAg protein). Recombinant HBx protein-based small interfering RNA (siRNA, short interfering RNA or silencing RNA) recovered interferon-1 activity by activating RIG-1 pathway. Nonetheless, detailed molecular determinants for potential recognition of HBV PAMPs by PRR still remain to be elucidated. This would increase the therapeutic armamentarium to include PRR agonists that would help in viral clearance [68-70].

Cellular Level Immune Activity in HBV Infection

NK cell dysfunction is also central to viral persistence in HBV infection. The ability of myeloid DCs to activate NK cells is impaired due to weak action in decreasing activating cytokines (IL-6, IL-12, IL-18) resulting in reduced secretion of interferon- $\gamma$ and lowered activity of interferon- $\alpha$. IL-10 secretion from Kupffer cells (liver resident macrophages) promotes cytokine blunting and hence lowers NK activation. IL-10 is an immune-suppressive cytokine (also secreted by virus-specific B lymphocytes) that maintains the immune tolerance during persistent HBV infection. Programmed death-ligand 1 (PD-L1) on suppressive monocytes also inhibit autologous NK cell activation. Reduction in the NK-cell mediated cytotoxic prowess and IFN- $\gamma$ production contribute to HBV persistence. The expression of activating receptors on NK cells such as the NKG2D and 2B4 are also reduced in chronic HBV infection.

The myeloid-derived suppressor cell (MDSC) with predominant granulocytic subset (gMDSC) and monocytic MDSC (mMDCS) has an inverse relation with T cell function and hepatitis in chronic HBV infection. MDSCs potentiate CD4+ and CD8+ T cell responses via arginase-dependent pathways. High arginase levels reduce amount of arginine required for lymphocyte physiology and growth and resulting in lymphocyte dysfunction. Disruption of MDSC differentiation and T-regulatory cells (Tregs) resulted in immunosuppressive cytokine reduction which inhibited HBV replication. NKT cells of a special subset of T lymphocytes that express surface markers of T lymphocytes and NK cells - the invariant NKT cells (iNKT) lose functionality in the presence of HBV infection through an increase in T-cell immunoglobulin and mucin domain-3 (Tim-3) and programmed cell death protein 1 (PD-1) - antiviral treatment or Tim-3 blocking restores immune function of iNKT cells and improves viral clearance [71-74].

Interferon- $\gamma$ secreted by lymphocytes in HBV infection induces Kupffer cells to produce chemokine (C-X-C motif) ligand 9 (CXCL9) and recruits HBV-specific CD4 + T lymphocytes to enter the liver for apoptosis, leading to chronic HBV. Defects in CD8 + T-lymphocyte functions through multiple pathways [blunted cytokine responses, T-lymphocyte depletion, high expression of co-inhibitory molecules such as Tim-3, PD1 and CTLA-4, upregulation of TNF-related apoptosis-inducing ligand (TRAIL), arginase secretion] result in reduced HBV clearance from hepatocytes. PD-1 blockade can partially restore B cell function and CD 8+ T cell functions for viral clearance. Higher level of T helper cell 17 (Th17) lymphocytes (secretes IL-17, IL-21, IL-22) in the liver and peripheral blood was associated with acute and acute on chronic liver failure due to HBV. In chronic HBV infection, a follicular helper T (Tfh) cells response to HBsAg was required for HBV clearance which was blocked by Treg cells [75-82].

Endoplasmic reticulum (ER) stress also plays an important role in viral persistence. In HBV-infected cells, a large number of viral surface proteins are folded in ER during the replicative phase, resulting in disruption of ER homeostasis and ER stress. This is identified as ground-glass hepatocytes that accumulate ER mutant surface proteins (pre-s1 and pre-s2 mutants) which represent ER hypertrophy. ER stress leads to activation of ER degradation enhancers and hence reduction in the immune responses for viral clearance. The intracellular imbalance in favor of L-HBs compared with M- and S-HBs leads to ER stress, which can trigger cellular signals for apoptosis or uncontrolled cellular growth [83]. HBV RNA directly degrades host microRNA (miRNA, which is non-coding) leading to reduction in levels of miRNA-122 [block fibrosis by blocking collagen synthesis via transforming growth factor beta (TGF- $\beta$ ) pathway], miRNA-15 family and miRNA-let7 family which lead to increased HBV replication, liver fibrosis and carcinogenesis [84-90]. Based on our current understanding of HBV immunopathogenesis, novel treatment strategies for enhancing chances for clinical cure of chronic HBV infection include PRR, TLR7 or RIG-I agonists (increases innate immune responses), PD-1 blockade (immune checkpoint blockers), therapeutic vaccines (based on miRNA), and chimeric antigen receptor $\mathrm{T}$ lymphocytes that improve adaptive immune responses for enhancing viral clearance. Figure 2 summarizes an updated schematic of the pertinent immunopathogenic processes and therapeutic targets in HBV infection. 


\section{Cureus}

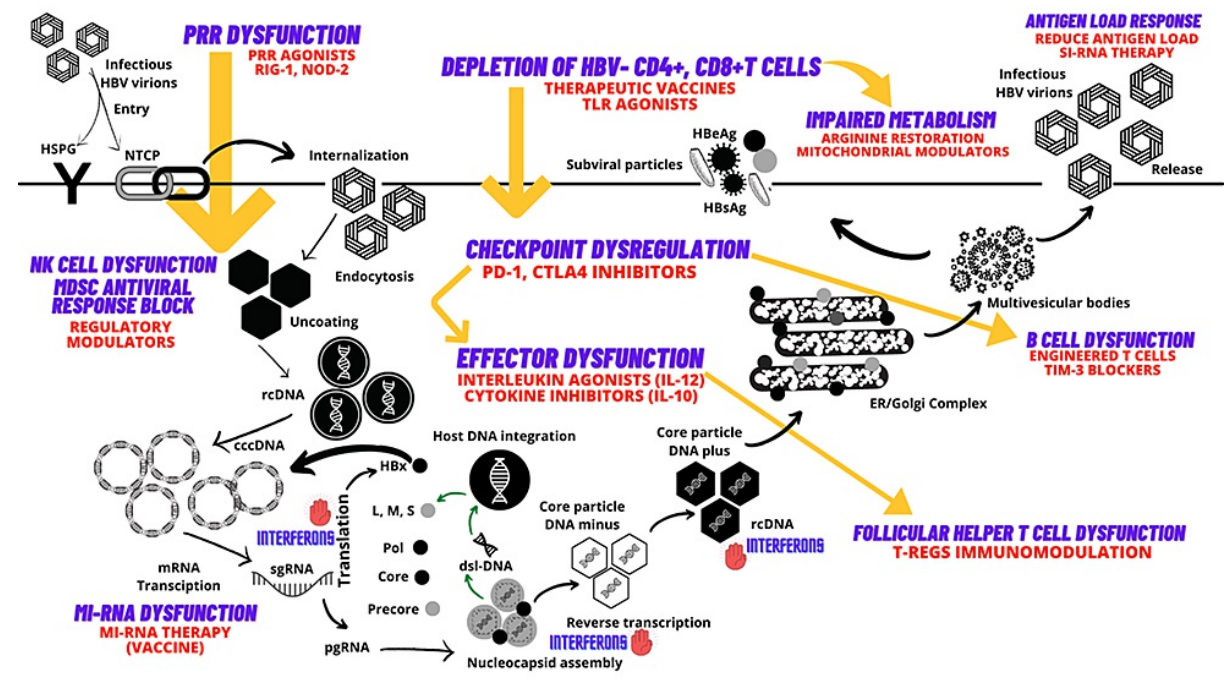

FIGURE 2: Schematic representation of hepatitis B virus (HBV) immunopathogenesis and immune targets of new antiviral therapies.

HSPG - heparin sulfate proteoglycans, NTCP - Sodium taurocholate co-transporting polypeptide, TLR - toll-like receptors, $C D$ - cluster of differentiation, PRR - pattern recognition receptors, $P D$ - programmed cell death protein, CTLA - cytotoxic T-lymphocyte-associated protein 4, Tregs - T-regulatory cells, IL - interleukins, TIM-3 - T cell immunoglobulin and mucin domain-containing protein 3, miRNA-micro-RNA, NK - natural killer cells, MDSC - myeloid-derived suppressor cell, HBeAg - HBV envelope antigen, HBsAg - HBV surface antigen, ER endoplasmic reticulum, RNA-H - ribonuclease $\mathrm{H}$, rcDNA - relaxed circular DNA, cccDNA - covalently closed circular DNA, mRNA - messenger RNA, siRNA - small interfering RNA, pgRNA - pregenomic RNA, sgRNA subgenomic RNA, CPAM - core protein allosteric modulator, Pol - polymerase, $\mathrm{L}$ - large HBsAg, $\mathrm{S}$ - small HBsAg, M - medium HBsAg

\section{Updates on HBV genotypes and their clinical importance}

Currently, 10 genotypes of HBV exist, with additional subtypes (mutations or recombinant strains), which are identified by the letters A to J and numbered respectively, which, through genetic mutations and the lack of proofreading in reverse transcriptase, have evolved over the long term, creating challenges to their elimination. An example is the HBV genotype B2 which is a recombinant, with majority of the genetic framework from HBV genotype B, and the precore/core region from genotype C. Coinfection with different HBV genotypes and intergenotypic recombination of HBV strains are extensively documented. Most commonly associated recombinants include genotypes B/C or A/D. Each genotype is classified by an $8 \%$ or more divergence in the nucleotide sequence of the genome. Genotypes A to D are the four predominant genotypes; B and C are most common in eastern and southeastern Asia, A and D are found in North America, Africa and Europe and genotype $\mathrm{E}$ is found in West Africa. Genotypes A and B have a greater response to interferon therapy than $\mathrm{C}$ and $\mathrm{D}$, but none of the genotypes have differential responses to oral antivirals [91-93]. Delayed HBeAg seroconversion and a higher risk of reactivation in the HBeAg-negative phase were notable in HBV patients with genotype $C$ who also have more advanced fibrosis. Liver cancer develops in young patients without cirrhosis who harbor HBV genotype B-related infection. Patients with HBV genotypes $\mathrm{C}$ and $\mathrm{D}$, compared with genotypes $\mathrm{A}$ and $\mathrm{B}$, have late or absent $\mathrm{HBeAg}$ seroconversion after multiple hepatitis flares that accelerate progression of liver disease, conferring worse clinical outcome. HBV genotypes are also associated with specific virological manifestations such as higher frequency of basal-core promoter A1762T/G1764A variants, pre-S deletion mutations, greater viral replicative burden, expression of intracellular HBV DNA and core protein expression and HBeAg secretion in genotype $C$ when compared with other genotypes. In a systematic review and metanalysis, authors found that the blood group B was associated with a lower risk of HBV infection and persons with blood group $\mathrm{O}$ had a $12 \%$ increased risk of HBV infection in endemic regions [94-97].

\section{Evaluation and treatment of HBV related liver disease}

Current Approaches to Diagnosis and Evaluation

Presence of HBsAg indicates acute or chronic infection and is the first serologic marker to appear. HBV infection is considered chronic if HBsAg persists beyond six months. The HBeAg indicates active replication while its absence can also indicate mutations in the pre-core region of the e-antigen that prevent production of HBeAg. Antibody response to $\mathrm{HBeAg}$ (anti-HBe) indicates that the virus is non-replicative, but is also seen among HBV patients with HBeAg mutation with active disease. Antibody to HBc antigen can be present in acute infection and reactivation (IgM) and with past exposure to HBV (IgG). It can be seen in solitude when antibody response to HBsAg is waning. Patients who are HBsAg-positive and anti-HBc- 
positive need further evaluation for initiation of treatment. Those who are anti-HBs-positive and anti-HBcpositive are considered to have infection in the past and currently resolved. Nonetheless, in these patients infection may remain latent, only to reactivate under special circumstances (immunosuppression, spontaneous mutation) along with re-emergence of HBsAg. Patients who are HBsAg, anti-HBs, and anti-HBc negative do not possess immunity needs vaccination. Patients who are only anti-HBs-positive are immune or have undergone vaccination [98-100].

In patients who are $\mathrm{HBsAg}$ and antibody (total) to $\mathrm{HBcAg}$ positive, further differentiation is made on the presence or absence of HBeAg after which classification into chronic infection and chronic hepatitis is made for treatment decisions. Patients with chronic infection have normal alanine aminotransferase (ALT) and no or minimal liver damage (fibrosis grade $<2$ ) while those with chronic hepatitis have elevated HBV DNA and ALT with ongoing necro-inflammatory liver damage or significant fibrosis (grade $\geqslant 2$ ), for whom treatments are to be directed $[101,102]$. The alanine transaminase concentrations generally correlate with hepatic necroinflammation in HBV patients. High-normal ALT levels ranging from 40 to 70 IU/liter are linked to cirrhosis and liver-related deaths. Currently, guidance on recommendations suggests that the ALT cutoffs should be $35 \mathrm{U} /$ liter for males and $25 \mathrm{U} /$ liter for females and significant elevation is considered two times the upper limit of normal (ULN). Even though percutaneous liver biopsy and histological interpretation is the gold standard for fibrosis assessment, its use in clinical practice is limited and follow-up biopsies are not routinely employed due to patient unacceptance. In this regard, assessment of hepatic fibrosis by noninvasive modalities is suggested. These include shear wave elastography (transient, acoustic radiation force impulse, or multidimensional) as well as magnetic resonance elastography (MRE). Among these the FibroScan ${ }^{\circledR}$ transient elastography is the best validated worldwide. In obese patients and those with ascites, MRE is to assess liver stiffness measurement (LSM) with phase contrast imaging is suggested, which can also stage even mild fibrosis, but it is less cost effective, not well tolerated and more time consuming than ultrasound methods. Other validated serum biomarker combinations for diagnosis of significant fibrosis in HBV patients include the aspartate aminotransferase (AST)-to-platelet ratio index (APRI, low sensitivity in African patients), the Forns index, Fibrotest ${ }^{\circledR}$, Fibrosure ${ }^{\mathrm{TM}}$, Fibrometer ${ }^{\circledR}$ and enhanced liver fibrosis $\left(\mathrm{ELF}^{\mathrm{TM}}\right)$ score [103-106].

There are three types of treatment end points or cure in HBV infection. In functional cure, there is resolution of clinical infection which is sustained off drug treatment - no inflammation, normal ALT level and normal liver biopsy, HBsAg seroclearance (equal to $0.05 \mathrm{IU} / \mathrm{ml}$ in serum) with or without the emergence of anti-HBs. Protective immunity is when the anti-HBs level is greater than $10 \mathrm{IU} / \mathrm{ml}$. Complete cure is virologic cure, consisting of all the elements of functional cure plus loss of cccDNA within the liver. In clinical practice, most of the treated patients fall into an interim cure period in which there is disease inactivity - absence of inflammation (normal ALT level and liver biopsy), low or undetectable HBV DNA level in the presence of HBsAg positivity. In this situation, a patient with chronic hepatitis is effectively down staged to one with chronic infection. An HBsAg level of $100 \mathrm{IU} / \mathrm{ml}$ in Asian HBeAg-negative patients is predictive of spontaneous HBsAg seroclearance within six to eight years. Inactive - low replicative chronic HBV patients have high rates of spontaneous HBsAg seroclearance, $-8.1 \%$ and $44.7 \%$ after 10 and 25 years of follow-up, respectively [107-110]. In a nutshell, HBsAg patients who require treatment with antiviral agents include patients with chronic hepatitis, those with cirrhosis (any level ALT, detectable HBV DNA and decompensated patients irrespective of DNA and ALT levels), those with hepatocellular carcinoma (HCC), HIV coinfection, on chemotherapy or biologic and immunomodulatory agents, women in the third trimester of pregnancy if HBV DNA is greater than 200,000 IU/mL and those with extrahepatic manifestations such as glomerulonephritis and vasculitis $[111,112]$. A summary of various international guidelines for the management of chronic HBV is shown in Table 1. 


\section{Cureus}

\begin{tabular}{|c|c|c|c|c|c|}
\hline Management & WHO 2015 & ATA 2015 & APASL 2015 & EASL 2017 & AASLD 2018 \\
\hline $\begin{array}{l}\text { When to } \\
\text { initiate }\end{array}$ & $\begin{array}{l}\text { Compensated or } \\
\text { decompensated cirrhosis } \\
\text { (or APRI }>2 \text { in adults) } \\
\text { Age }>30 \text { yr, persistently } \\
\text { abnormal ALT, and HBV } \\
\text { DNA }>20,000 \text { IU/mI HBV } \\
\text { DNA not available, then on } \\
\text { bases of persistently } \\
\text { abnormal ALT levels }\end{array}$ & $\begin{array}{l}\text { ALT level }>2 \times U L N \text { and HBV } \\
\text { DNA >2,000 IU/ml } \\
\text { Compensated/decompensated } \\
\text { cirrhosis with detectable HBV } \\
\text { DNA }\end{array}$ & $\begin{array}{l}\text { ALT }>2 \times U L N \text { and } \\
\text { HBV DNA }>2,000 \\
\text { IU/ml in HBeAg } \\
\text { negative or }> \\
2,000 \mathrm{IU} / \mathrm{ml} \text { in } \\
\text { HBeAg-positive } \\
\text { Compensated or } \\
\text { decompensated } \\
\text { cirrhosis with } \\
\text { detectable HBV } \\
\text { DNA }\end{array}$ & $\begin{array}{l}\text { HBV DNA }>2,000 \text { IU } / \mathrm{ml} \text {, ALT } \\
>\text { ULN and moderate liver } \\
\text { necro-inflammation or } \\
\text { fibrosis (F2 minimum) } \\
\text { Compensated or } \\
\text { decompensated cirrhosis } \\
\text { with detectable HBV DNA } \\
\text { HBV DNA >20,000 IU/ml and } \\
\text { ALT } \geq 2 \times \text { ULN HBeAg } \\
\text { positive, high HBV DNA } \\
\text { level, and age } 30 \text { yr Family } \\
\text { history of HCC, cirrhosis, } \\
\text { extrahepatic manifestations }\end{array}$ & $\begin{array}{l}\text { ALT }>2 \times \text { ULN } \\
\text { and HBV DNA } \\
>2,000 \text { IU/ml in } \\
\text { HBeAg negative } \\
\text { or }>20,000 \text { IU/ml } \\
\text { in HBeAg positive } \\
\text { Cirrhosis with } \\
\text { HBV DNA > 2,000 } \\
\text { IU/ml Age } 40 \mathrm{yr} \text {, } \\
\text { family history of } \\
\text { HCC, previous } \\
\text { treatment, } \\
\text { extrahepatic } \\
\text { disease }\end{array}$ \\
\hline $\begin{array}{l}\text { What to treat } \\
\text { with }\end{array}$ & ETV, TDF & ETV, TDF, Peg IFN- $\alpha$ & $\begin{array}{l}\text { ETV, TDF, Peg } \\
\text { IFN- } \alpha \text { or LAM } \\
\text { ADV and LdT (less } \\
\text { preferred) }\end{array}$ & ETV, TDF, TAF, Peg IFN- $\alpha$ & $\begin{array}{l}\text { ETV, TDF, Peg } \\
\text { IFN- } a\end{array}$ \\
\hline When to stop & $\begin{array}{l}\text { Lifelong treatment in } \\
\text { cirrhosis Stop treatment if } \\
\text { non-cirrhotic, HBeAg } \\
\text { seroconversion, or } \\
\text { persistently normal ALT } \\
\text { levels with or without } \\
\text { undetectable HBV DNA } \\
\text { Stop treatment in case of } \\
\text { persistent HBsAg loss with } \\
1 \text { yr of consolidation } \\
\text { therapy }\end{array}$ & HBsAg loss for 6-12 mo & $\begin{array}{l}\text { least } 12 \text { mo Non- } \\
\text { cirrhotic HBeAg } \\
\text { seroconversion } \\
\text { and undetectable } \\
\text { HBV DNA after } \\
\text { minimum } 1 \mathrm{yr} \\
\text { (preferably } 3 \mathrm{yr} \text { ) of } \\
\text { consolidation } \\
\text { therapy Non- } \\
\text { cirrhotic HBeAg } \\
\text { negative and } \\
\text { undetectable HBV } \\
\text { DNA for } \geq 2 \text { yr }\end{array}$ & $\begin{array}{l}\text { HBsAg loss Non-cirrhotic } \\
\text { HBeAg positive with } \\
\text { seroconversion and } \\
\text { undetectable HBV DNA after } \\
12 \text { mo of consolidation } \\
\text { therapy Noncirrhotic HBeAg } \\
\text { negative with undetectable } \\
\text { HBV DNA for } 3 \mathrm{yr}\end{array}$ & $\begin{array}{l}\text { HBsAg loss } \\
\text { Lifelong in } \\
\text { cirrhosis }\end{array}$ \\
\hline Retreatment & Reactivation of HBV & $\begin{array}{l}\text { Relapse of HBV with respect } \\
\text { to HBV DNA and ALT levels } \\
\text { (specific levels not provided) }\end{array}$ & None & $\begin{array}{l}\text { Similar to treatment-naive } \\
\text { patients }\end{array}$ & None \\
\hline
\end{tabular}

\section{TABLE 1: Summary of guidelines for treatment of chronic hepatitis B virus infection}

WHO - World Health Organization, ATA - American Treatment Association, APASL Asia-Pacific Association for the Study of Liver, EASL - European Association for the Study of Liver, AASLD - American Association for the Study of Liver Diseases, APRI - aspartate transaminase (AST) to Platelet Ratio Index, HBV - hepatitis B virus, ALT - alanine aminotransferase, ULN - upper limit of normal, ETV - entecavir, TDF - tenofovir disoproxil, TAF - tenofovir alafenamide, IFN - interferon, LAM - lamivudine, ADV - adefovir, LdT - telbivudine

It is important to note that among HBsAg-positive cases who additionally suffer from obesity or metabolic syndrome, the risk of development of cirrhosis is higher than those with HBV infection alone [111,112]. In these patients, if HBV DNA level is low or undetectable then the abnormal ALT level may be due to nonalcoholic fatty liver disease (NAFLD) which requires targeted treatments and lifestyle modifications with close follow up. However, in those with increasing ALT, only a liver biopsy can help differentiate between NAFLD-related liver disease or HBV-associated necro-inflammation. Current literature suggests that patients in the immune tolerance phase or HBeAg positive chronic infection (very high HBV DNA $>10^{7}$ $\mathrm{IU} / \mathrm{mL}$ and normal ALT) if aged above 30-40 years benefit from antiviral therapy irrespective of other standard inclusions for treatment initiation. Nonetheless, one must be aware that spontaneous HBeAg and HBsAg clearance with remission of liver disease can occur in $70-80 \%$ of patients at median follow up of approximately 10 to 20 years [113-115].

\section{New updates on diagnosis and monitoring}

The HBV core-related antigen (HBcrAg) is a new indicator that encompasses amino acid sequence common to $\mathrm{HBeAg}$ and $\mathrm{HBcAg}$ as well as the 22 -kDa precore protein. $\mathrm{HBcrAg}$ positivity correlates with intrahepatic HBV DNA and pregenomic RNA levels among patients on antiviral treatment. This makes HBcrAg 
measurement a good serum marker of the active transcriptional activity of liver cccDNA and higher levels correlate with increased risk of hepatocellular carcinoma [116-118]. Another potentially new viral marker for future clinical use is measurement of HBV RNA which has been shown to provide significant insights into antiviral treatment response and cessation decision; identification of functional cure in chronic HBV infection; risk for HBV-related liver cancer and levels of intrahepatic HBV cccDNA. Particularly, the HBV pregenomic RNA reflects viral replication activity and could be a very valuable tool for monitoring the effect in patients receiving novel anti-HBV therapies. These viral molecules are promising as surrogate markers for HBV viral activity, and when used alongside standard biomarkers, they allow for better assessment of HBV infection and treatment responses [119-121]. Since carcinogenesis is an important aspect in the natural history of HBV-related infection, the novel HBV DNA quantitation-time index (HDQTI), comprising HBV DNA quantitation and follow up, was found to predict HBV associated liver cancer prognosis identified a cut-off value at 34 . The HDQTI also predicted cancer recurrence and the need for shorter surveillance intervals with appropriate imaging in patients with a high score [122]. Liver biopsy can be avoided in a significant number of patients with use of the combined ELF ${ }^{\mathrm{TM}}$ (based on Fibroscan ${ }^{\circledR}$ ) algorithm. The optimal cut-off values of ELFTM ${ }^{\mathrm{TM}}$ were 8.4 to exclude advanced fibrosis, and 10.8 to confirm advanced fibrosis and LSM $\leqslant 6.0 \mathrm{kPa}$ and $\leqslant 7.5 \mathrm{kPa}$ excludes $\geqslant F 3$ fibrosis while LSM $>9.0 \mathrm{kPa}$ and $>12.0 \mathrm{kPa}$ diagnose $\geqslant F 3$ fibrosis in normal and elevated (1-5× ULN) ALT, respectively [123].

Streamlining the HBV diagnostic process to identify those who would benefit from screening, surveillance or therapy through artificial intelligence-related machine learning (ML) is a novel technique. With the help of ML, a predictive model for inflammation grades of chronic HBV was proposed utilizing a combination of gene expression data and three clinical parameters (ALT, AST, HBV DNA) over which a user-friendly web tool (LiveBoost $^{\mathrm{TM}}$ ) was applied for the clinical prediction of hepatic fibrosis. It was demonstrated that the ML system outperformed FIB-4 scoring in predicting advanced hepatic fibrosis. Additionally, an artificial neural network (ANN) model was found to be effective in diagnosing liver fibrosis regression in HBV patients on therapy. ML-based models were also found to accurately identify persons at risk for HBsAg positivity, predict HBsAg seroclearance, predict treatment decisions in HBV carriers; 28- and 90-day mortality of HBV related ACLF, determine viral variants; and interactions between viral and host proteins to map pathways in hepatocellular carcinoma [124-128].

\section{Current measures and updates on prevention and treatment}

The immunogenic first-generation active HBV vaccines were made from materials extracted directly from plasma of chronically HBV-infected patients. It was not the virions that were utilized, but the large amounts of non-infectious spherical viral particles in carrier plasma, which were easily separated by biophysical methods. After cloning the HBV genome, large-scale production of spherical viral particles within recombinant yeast cells (yeast-derived second-generation vaccines) showed comparable protection with plasma-derived vaccines. Vaccine response rates with yeast-derived vaccines are>99\% among infants and adolescents, but insufficient in $5 \%$ of healthy adults. The majority of yeast-derived vaccines consist only of the S-HBs of the globally underrepresented HBV genotype A2, dominant only in Northern Europe and North America. Very high anti-HBs titers $(>1,000 \mathrm{IU} / \mathrm{L})$ are protective, but low or waning anti-HBs-titers over time increase risk of breakthrough infection with antigenically distant HBV genotypes (HBV genotypes B, C, D and $\mathrm{F}$ and at anti-HBs titers of less than $100 \mathrm{IU} / \mathrm{L}$ ). The minimal infectious dose of $\mathrm{HBV}$ is as low as 16 virions (or 3 IU) when transmission occurs through HBV-contaminated blood transfusions [129-132].

Current therapies for the management of HBV include interferon- $\alpha$ (standard or pegylated) and orally administered NAs. First-line therapy should be with an oral antiviral with a strong genetic barrier to viral resistance such as either entecavir, tenofovir disoproxil (TDF) or tenofovir alfenamide (TAF, prodrug of TDF with more stable concentration in serum hence lower dose and less systemic exposure). Short-term treatment with NA is feasible in HBeAg-positive patients experiencing seroconversion to anti-HBe during treatment. A randomized controlled study (FINITE) analysed outcome when TDF therapy was withdrawn in a set of HBeAg negative patients who had achieved suppression of HBV DNA. Interestingly, $43 \%$ of patients achieved either HBsAg loss or suppressed DNA without any significant safety concerns [133-136].

Peginterferon for chronic HBV-related hepatitis is not widely used, even though the treatment period is finite (48 wks therapy). For HBeAg positive patients with low HBV DNA $\left(<2 \times 10^{8} \mathrm{IU} / \mathrm{mL}\right)$, genotype A, and elevated serum ALT ( $>2-5$ times ULN) along with necroinflammation on liver biopsy, peginterferon- $\alpha$ could be used as first-line antiviral agent. HBeAg negative, genotype D patients who do not experience decrease in HBsAg levels and $2 \log 10 \mathrm{IU} / \mathrm{ml}$ reduction of HBV DNA at 12 weeks peginterferon- $\alpha$ treatment are considered non-responders. The HBsAg level is useful for prediction and motoring of response to therapy with peginterferon. HBeAg-positive patients, with HBsAg level of 20,000 IU/ml at week 24 are considered nonresponders and treatment can be stopped early. Peginterferon leads to higher rates of HBeAg and HBsAg loss at one year mainly in patients with genotype A infection. Overall rates of sustained response ( $\mathrm{HBeAg}$ seroconversion and undetectable HBV DNA in HBeAg positive patients and DNA <2000 IU/mL in HBeAg negative patients) after a one-year course of treatment is $27-36 \%$ and $28 \%$ respectively. Combination of NA and peginterferon can be performed via two protocols - de novo combination or the simultaneous administration of the two agents in treatment-naïve HBV patients; and the sequential combination, which features "add-on" or "switch-to" strategy in those who are already on treatment with either drug. This strategy improves HBsAg loss. Nonetheless, the benefits are mainly limited to specific group of patients - 
those with low baseline HBsAg level and on-treatment HBsAg response, high baseline ALT and viral load and genotype A. Peginterferon should not be used in decompensated cirrhosis, but can be used with caution in patients with compensated cirrhosis [137-139].

For those with chronic HBV hepatitis and multiple drug-resistant virus strains, combination of TDF and entecavir seems to be an effective and safe rescue option. In general, after HBeAg seroconversion, the treatment should continue for at least one year and possibly an additional three years to achieve longlasting response once therapy is discontinued [137,139]. This three-year continuation phase lowers relapse rates to $<30 \%$ and hastens loss of HBsAg. Nonetheless, higher relapse rates after NA discontinuation occur in older patients and those with HBV genotype C infection. Ideally, NAs can be withdrawn in HBeAg negative patients only after confirmed loss of HBsAg, with or without antibody development. Recommendations from European and Asian countries suggest stopping of NAs in HBeAg-negative patients who have undetectable HBV DNA at three different times points, six months apart $[139,140]$. One should not stop NA in patients with cirrhosis. Long-term NA therapy can decrease the cccDNA pool of infected hepatocytes through inhibition of nucleocapsid recycling but cannot prevent the initial cccDNA formation in newly infected hepatocytes [140,141].

In patients with liver failure, benefits were observed in those with model for end-stage liver disease (MELD) score between 20-30, while the mortality rate in those with MELD > 30 was >90\% even in the presence of early antiviral treatment - these patients need early referral for liver transplantation [141,142]. After liver transplantation, antiviral therapy is indefinite, regardless of HBsAg, HBeAg, or HBV DNA status. For patients on immunosuppressive therapy, antiviral therapy should be continued for at least six to 12 and 12 to 18 months after completion of therapy, as per American and European guidelines respectively; longer duration specifically in those receiving rituximab [142,143]. For pregnant HBV patients, antiviral therapy should commence at 28 weeks gestation and continued 12 weeks post-partum. For patients with HCV and HBV co-infection, entecavir has the least drug-drug interaction and treatment can be started simultaneously. In people living with HIV and HBV co-infection, the treatment should include either TDF or TAF + lamivudine or emtricitabine along with other HIV drugs [142-144].

\section{Future directions for HBV treatment}

HBV entry inhibitors targeting NTCP receptors include myrcludex-B (also called bulevirtide, subcutaneous route) and cyclosporine A (CsA). The former, a synthetic lipopeptide derived from pre-S1 domain blocks infection of new hepatocytes and hinders amplification of intrahepatic cccDNA of infected hepatocytes. The latter, a cyclic non-ribosomal peptide inhibit NTCP transporter activity blocking viral entry into hepatocytes - but can impair sodium dependent bile acid uptake resulting in various adverse events. Nonetheless, recently discovered SCY450 and SCY995 derivatives of CsA do not impair bile acid uptake $[145,146]$.

APOBEC3 cytidine deaminase activators (through lymphotoxin- $\beta$ receptor, LTBR pathway) via engineered non-lytic T cells with HBV-specific T-cell receptors inhibited HBV replication in small animal models. LTBR agonists were found to degrade cccDNA and exhaust intrahepatic pool. Genome-editing using transcription activator-like effector nucleases (TALENs), and the clustered regularly interspaced short palindromic repeats/Cas9 (CRISPR/Cas9) or locked nucleic acid technology (LNA) can be used to target specific DNA sequences for cleaving. TALENs comprise a nonspecific Fok1 nuclease domain fused to a customizable (can be engineered to target and disrupt any specific DNA sequence) sequence-specific DNA-binding domain. However, the safety of such DNA sequence cleavage on 'HBV integrated host genome' and its consequences remain to be studied. HBV-specific CRISPR/Cas system-mediated removal of the full-length integrated HBV DNA and the disruption of HBV cccDNA in a stable HBV cell line was demonstrated recently. CRISPR/Cas9 system from Streptococcus pyogenes and $S$. thermophilus targeting conserved regions of the HBV genome resulted in degradation of $>90 \%$ HBV cccDNA by six days. Nonetheless, even though deep sequencing revealed that Streptococcus-CRISPR/Cas9 had no effect on the host genome, it induced intrinsic off-target adverse effects such as mutagenesis [147-150].

RNA interference (RNAi) by which siRNA produces gene silencing at the post-transcriptional level to downregulate the expression of targeted genes is another novel therapeutic area. The siRNA therapeutic, ARC-520 that targets ccCDNA-derived pre-genomic RNA was found to reduce HBsAg levels in HBeAgpositive patients, but not HBeAg-negative patients as in the latter, HBsAg arises not from cccDNA pool, but from HBV DNA integrated with the host genome. The novel ARO-HBV (JNJ-3839), targeting two sources of HBsAg, pre-genomic and integrated DNA, is currently under evaluation. Another siRNA molecule called AB729 using novel conjugated N-acetyl galactosamine delivery technology with strong anti-HBV activity which acts on all HBV RNA transcriptions is under evaluation [151-153].

Virus nucleocapsid assembly inhibitors/modulators (heteroaryldihydropyrimidines that function to misdirect formation of aberrant or non-capsid structures; and phenylpropenamides or sulfamoylbenzamides that function to produce dysfunctional intact empty capsids) limit HBV replication by causing capsid destabilization is under multiple trials. A novel acyclic nucleotide phosphonate called besifovir is recently approved for trial studies. The main adverse event noted was L-carnitine depletion (myonecrosis, hypoglycemia) in treated patients requiring supplementation. Another new lipid conjugated nucleoside analogue under clinical development is tenofovir exalidex (TLX) which shows enhanced hepatic targeting 
that maximizes liver activity while reducing systemic drug exposure and was found to enhance HBsAg loss and reduce the cccDNA amount. Another novel nucleoside analogue under phase II clinical study is CMX157 [154-157]. Inhibitors of ribonuclease $\mathrm{H}$ ( $\alpha$-hydroxytropolones, $\mathrm{N}$-hydroxyisoquinolinediones and $\mathrm{N}$ hydroxypyridinediones) limit degradation of HBV pre-genomic RNA during DNA minus strand synthesis thereby permitting plus-strand synthesis are a novel class of antiviral agents that block release of infectious virions and amplification/replenishment of cccDNA pool. Inhibiting HBsAg release ameliorates T cell tolerance, reduces $\mathrm{T}$ cell exhaustion and restores HBV-specific T cell-mediated immune response. Phosphorothioated oligonucleotide assembly blockers are nucleic acid polymers that prevent assembly of subviral particles which are the primary source of circulating HBsAg. Designated REP 301 and REP 401, these drugs used along with NAs or peginterferon may have better chances at promoting functional cure [158-162].

Based on our advances in understanding immunopathogenesis of HBV, multiple immune modulating therapeutic agents are under development which would help promote functional cure of HBV. TLR agonists (TLR-7 - oral vesatolimod or selgantolimod and TLR-8) induce endogenous interferon production, activate innate responses, leading to induction of interferon-stimulated genes (also called STING agonists) and other signaling cascades that inhibit HBV replication. Nonetheless, phase II studies have shown that even though $\mathrm{T}$ cell increase, NK cell responses and interferon signaling were improved with TLR agonists, reduction in HBsAg levels were not identified. This means that monotherapy with these agents is probably of low clinical relevance and hence combination strategies are warranted. Pattern recognition receptor agonists such as RIG-I and NOD-2 agonists activate interferon signaling pathways and proinflammatory cytokines that improve viral clearance. The RIG-I agonist, inarigivir soproxil, a novel oral modulator of innate immunity when used along with TDF significantly increased reduction of HBV replication, HBV RNA and HBsAg levels in a dose-dependent manner in both HBeAg-positive and HBeAg-negative patients [163-165].

PD-1, a highly expressed inhibitory receptor on HBV-specific T cells, along with increased expression of PDL1 (PD-1 ligand), contributes to T cell exhaustion and high HBV replication in chronic HBV. Thus, PD-1/PDL1 pathway blockers induce proliferation of HBV-specific T cells, thus restoring functioning $\mathrm{T}$ cells and helping control HBV. A pilot study showed that the PD-1 blocker nivolumab along with HBV therapeutic vaccine GS-4774 achieved significant and sustained HBsAg loss [166-168]. Finally, the novel therapeutic protein-based vaccines that include subunit vaccines (HBsAg+HBcAg called HeberNasvac) and antigenantibody complex vaccines (HBsAg+HBV immunoglobulin) did not demonstrate favorable results due to non-induction of cytotoxic T cell responses. DNA-based vaccines encoding HBV envelope proteins such as INO-1800 (multi-antigen vaccine encoding HBsAg and consensus HBcAg sequence) that induce HBVspecific T cells; INO-9112 (encoding human IL-12); HB-110 (encoding HBsAg, pre-S1 Ag, HBcAg, HBV polymerase, human IL-12) are under evaluation. New vector-based vaccine GS-4774, a recombinant, heatkilled, Saccharomyces cerevisiae yeast-based vaccine expressing $\mathrm{HBsAg}, \mathrm{HBcAg}$, and $\mathrm{HBx}$, did not provide significant reductions in serum HBsAg levels when used alone, but induced strong immunomodulatory effects when used along with TDF. The non-replicative adenovirus 5 vector vaccine TG1050 encodes a large fusion protein made of modified HBV core, HBV polymerase, and selected envelope protein domains. TG1050 was found to have a good safety profile and induced appreciable HBV-specific cellular immune response in early trials [169-171].

In another study, 12 chemical compound candidates for alpha-glucosidase inhibitors were identified from a library of chemical compounds and used to treat fresh human hepatocytes infected with HBV and monitored for their anti-viral effects. It was found that HBV replication was inhibited by one candidate, a tetramethylpiperidinol derivative in a dose-dependent manner, through interaction with HBV nuclear transcription factor $\mathrm{Sp} 1$ which was also associated with significant reduction of cccDNA production, compared to entecavir [172]. To summarize (Table 2), novel therapeutic agents targeting functional cure for chronic HBV infection include entry inhibitors, cccDNA disruptors, translation inhibitors, capsid assembly blockers, polymerase and secretion inhibitors and state-of-the-art therapeutic vaccines [173-176]. 


\section{Cureus}

\begin{tabular}{|c|c|c|c|c|}
\hline Type of drug & Name of drug & $\begin{array}{l}\text { Clinical } \\
\text { trial } \\
\text { phase }\end{array}$ & Route & Mode of action \\
\hline Entry inhibitors & Myrcludex-B / Bulevirtide & II & Subcutaneous & HBV entry blockade \\
\hline Oligonucleotides & $\begin{array}{l}\text { INOIS-HBVRx (GSK3228836), } \\
\text { INOIS-HBVLRx (GSK33389404) }\end{array}$ & $\begin{array}{l}\text { II, } \\
\text { Preclinical }\end{array}$ & Subcutaneous & Antisense Antisense \\
\hline $\begin{array}{l}\text { Core protein } \\
\text { allosteric } \\
\text { modulators } \\
\text { (CpAMs) }\end{array}$ & $\begin{array}{l}\text { RO7049389 JNJ, 56136379 JNJ, } \\
64530440 \text { AB-506, ABI-H2158, } \\
\text { ABI-H0731 (Vebicorvir), GLS4JHS, } \\
\text { NVR 3-778 QL-007 }\end{array}$ & I to II & All oral & $\begin{array}{l}\text { Core protein binding Assembly modulation } \\
\text { Assembly modulation Core protein binding Core } \\
\text { protein binding Core protein binding Core } \\
\text { protein binding Assembly modulation Assembly } \\
\text { modulation }\end{array}$ \\
\hline $\begin{array}{l}\text { HBx protein } \\
\text { inhibitors }\end{array}$ & Nitazoxanide, CRV-431 & II, I & Oral Oral & cccDNA transcription Cyclophilin inhibitor \\
\hline RNA interference & $\begin{array}{l}\text { GSK3389404, ARO-HBV (JNJ- } \\
\text { 3989), AB-729, ALN-HBV (VIR- } \\
\text { 2218), ARC-520, DCR-HBVS }\end{array}$ & II to II & $\begin{array}{l}\text { Subcutaneous } \\
\text { or Intravenous } \\
\text { Subcutaneous }\end{array}$ & $\begin{array}{l}\text { RNA degradation RNA interference RNA } \\
\text { interference RNA degradation RNA interference } \\
\text { RNA interference }\end{array}$ \\
\hline $\begin{array}{l}\text { HBsAg release } \\
\text { inhibitors }\end{array}$ & $\begin{array}{l}\text { Nucleic acid polymers REP } 2139 \text { - } \\
\text { Ca, REP } 2165 \text { - Mg }\end{array}$ & II & $\begin{array}{l}\text { Intravenous } \\
\text { Intravenous }\end{array}$ & $\begin{array}{l}\text { Binding and prevents release of HBsAg surface } \\
\text { protein }\end{array}$ \\
\hline $\begin{array}{l}\text { HBsAg } \\
\text { neutralization }\end{array}$ & GC 1102 (Lenvervimab) & II & Intravenous & Neutralization and inhibiting reentry \\
\hline $\begin{array}{l}\text { Inhibitors of } \\
\text { cccDNA }\end{array}$ & TALENs CRISPR-Cas9 & Preclinical & Unknown & cccDNA disruption cccDNA disruption \\
\hline $\begin{array}{l}\text { innate immune } \\
\text { responses (Toll-like } \\
\text { receptor agonists) }\end{array}$ & $\begin{array}{l}\text { RO7020531 Vesatolimod, GS- } \\
9620 \text { Selgantolimod, GS-9688 } \\
\text { AIC649 }\end{array}$ & I to |I & $\begin{array}{l}\text { Oral, Oral, } \\
\text { Oral }\end{array}$ & $\begin{array}{l}\text { TLR-7 agonist TLR-7 agonist TLR-8 agonist } \\
\text { TLR-9 agonist }\end{array}$ \\
\hline inhibitors & Nivolumab , Cemiplimab & I, I/II & Intravenous & PD-1 blockade PD-1 blockade \\
\hline $\begin{array}{l}\text { Therapeutic } \\
\text { vaccines }\end{array}$ & $\begin{array}{l}\text { ChAdOx1 HBV, Hep-Tcell, JNJ- } \\
64300535 \text {, GS-4774 }\end{array}$ & | to $\mid 1$ & $\begin{array}{l}\text { Subcutaneous } \\
\text { or } \\
\text { intramuscular }\end{array}$ & $\begin{array}{l}\text { ChAd+MVA vector HBV peptide+ TLR9 } \\
\text { adjuvant IC31 Electroporation DNA vaccine } \\
\text { DNA vaccine }\end{array}$ \\
\hline
\end{tabular}

\section{TABLE 2: Summary of novel antiviral therapies for chronic HBV infection}

HBV - hepatitis B virus, ccc- covalently closed circular, $\mathrm{Ca}$ - calcium, Mg - magnesium, TALENs - transcription activator-like effector nucleases, CRISPRCas9 - CRISPR-associated protein 9, TLRs - Toll-like receptors, PD - programmed death cell receptor, MVA - Modified Vaccinia Ankara, E - intramuscular - electroporation and intramuscular

\section{Updates on HBV-related ACLF}

Acute on chronic liver failure is a recently described entity in the natural history of cirrhosis, defined by acute insult leading to rapid hepatic decompensation, multiple organ failure and a high risk of short-term mortality, usually less than four weeks. Acute alcoholic hepatitis, drug-induced liver injury, infections and surgical stress are the most frequent precipitants for ACLF. Central to the pathophysiology of ACLF is the state of unchecked persistent inflammation and immune dysfunction with increased propensity to sepsis and organ failure. Reactivation of chronic HBV infection is an important and modifiable cause for ACLF $[177,178]$. Studies have reported an approximately $35 \%$ incidence of ACLF in patients with underlying HBVrelated cirrhosis who suffered from acute decompensation. A large Chinese study estimated that the overall ACLF incidence rate over a 10-year period was 2.53 per 100,000 of the general population per year. The short-term mortality of HBV-associated ACLF is high, with 28 -day mortality ranging from $40 \%$ to $50 \%$ depending on the diagnostic criteria as well as class and grade of ACLF. HBV infection was the most common acute insult precipitating HBV-associated ACLF in close to $60 \%$ of cases according to published data. The Asia-Pacific Association for Study of Liver ACLF Research Consortium (AARC) reported that acute viral hepatitis A and E contribute to $12.6 \%$ of acute insults, whereas a more recent study from the same group in ACLF revealed that complementary and alternative herbal medicines were the commonest cause for druginduced ACLF $[179,180]$. 
In HBV-related ACLF, viral factors were found to have strong association with the development of the catastrophic syndrome. The HBV basal core promoter/precore mutations such as T1753V, A1762T, G1764A, A1846T, G1896A, and G899A correlated with an increased risk of HBV-related ACLF which was supported by the fact that ACLF patients had distinct quasi-species characteristics and higher complexities and diversification within the precore/core gene [181].

A genome-wide association study identified HLA-DR and rs3129859*C allele as the major locus for susceptibility to HBV-related ACLF. This allele was associated with prolonged prothrombin time, faster progression to ascites development and higher 28-day mortality in HBV-ACLF. The authors concluded that the HLA class II restricted CD4+ T-cell pathway on the immunopathogenesis of HBV-related ACLF [182]. Some studies have also shown that HBV genotype B was more susceptible to developing ACLF while this has been refuted in a large metanalysis [183].

Prognosis of HBV-ACLF can be ascertained by a variety of scoring systems which include the standard MELD and MELD-sodium (MELD-Na) scores, EASL chronic liver failure (CLIF)-Consortium-ACLF score (CLIF-C ACLF, better prognostic tool than MELD), integrated MELD, which includes hepatic encephalopathy and age, with an improved sensitivity of approximately 70-80\% and the recently proposed AARC score, which integrates bilirubin, creatinine, prothrombin time, lactate, and hepatic encephalopathy which was found to be superior to the MELD in predicting outcomes $[177,179,184]$. Novel biomarkers such as serum M30 and M65 antigen and Golgi protein 3 - cell death markers were found to predict mortality in patients with HBVACLF. However, these have low sensitivity and are not routinely available for use [177,179]. Recently, multiple prediction models were devised by various authors looking at outcomes in patients with HBV-ACLF. One group found that hepatic encephalopathy, neutrophil percentage and platelet levels were independent risk factors for predicting the prognosis of HBV-ACLF. A new prediction model LR(p) was found to have better prediction accuracy than MELD, MELD-Na, and albumin-bilirubin (ALBI) scores [185]. In another study, multivariate analysis indicated that red cell distribution width, neutrophil-to-lymphocyte ratio (NLR), total bilirubin, serum creatinine and international normalized ratio (INR) were identified as risk factors for 90-day mortality in patients with HBV-ACLF. A risk assessment model, called the RNTIC, with cut-off value of 3.08 (sensitivity: $77.89 \%$, specificity: $86.04 \%$ ) was found to be more predictive of prognosis than MELD, MELD-sodium and Child-Pugh scores [186].

The NLR was also found to be an independent predictor of mortality in patients with HBV-ACLF undergoing treatment with artificial liver support systems (ALSS; combined plasma exchange and bilirubin adsorption performed with continuous renal replacement therapy machine and bilirubin absorbent column) suggesting that liver function in most patients with baseline NLR $\leqslant 3$ recovered with ALSS treatment, and those with NLRs $>6$ require emergency liver transplantation [187]. The Chinese Group on the Study of Severe Hepatitis $\mathrm{B}$ (COSSH) found that regardless of the presence of cirrhosis, patients with HBV, total bilirubin $\geqslant 12 \mathrm{mg} / \mathrm{dL}$ and INR $\geqslant 1.5$ should be diagnosed with ACLF. The COSSH prognostic score $(0.741 \times \mathrm{INR}+0.523 \times \mathrm{HBV}$ SOFA $+0.026 \times$ age $+0.003 \times \mathrm{TB}$ ) for short-term mortality was superior to five other scores based on both discovery and external validation studies [188]. Additionally, the HINT score, a novel prognostic score based on hepatic encephalopathy, INR, neutrophil count, and thyroid-stimulating hormone (TSH), was simpler and superior to the Child-Pugh, MELD, CLIF-SOFA, and CLIF-C ACLF scores and at least comparable with the COSSH-ACLF score. Sequential measurement of TSH was also helpful in prediction of poor outcomes in HBV-ACLF patients [189].

The age-bilirubin-international normalized ratio-creatinine (ABIC) score $>9.44$ was superior to the MELD score in predicting short-term survival (one and three month) in HBV-ACLF patients [190]. Another Chinese study found that the plasminogen (significantly lower in HBV-ACLF non-survivors than in survivors) was a good prognostic biomarker and sequential plasminogen measurements help identify clinical course of HBVACLF. A new score, known as "the P5", incorporating plasminogen levels, hepatic encephalopathy occurrence, age, INR and total bilirubin, was significantly superior to the Child-Pugh, MELD and CLIF-C ACLF scores [191]. A study evaluating the 'regenerating' ability of the liver showed that overall survival rate within 180 days was $43.48 \%$, and $\log 10$-AFP (alfafeto protein) $\geqslant 2.04$ indicated a better prognosis with $76.9 \%$ specificity and $62.5 \%$ sensitivity for patients with HBV-related ACLF. A new prognostic model called the TACIA score (including total bilirubin, age, creatinine, INR and AFP) was found to predict short-term outcomes in patients with HBV-ACLF in that, patients with lower TACIA scores (<4.34) survived longer [192]. A Chinese group found that low AFP (log value $<4.18$ ) was associated with worse prognosis in patients with HBV-ACLF treated with liver support devices and a new model containing AFP, called ALSS-prognosis model (APM - log value of AFP in microgram/L, INR, bilirubin, age, grade of encephalopathy and serum sodium), which showed potentially better prediction performance than MELD, MELD-Na, and CLIF-C ACLF score for short-term outcomes [193]. A collaborative study on HBV-ACLF utilized the classification and regression tree (CART) analysis to group patients into low and high risk. CART analysis identified three factors prognostic of survival: hepatic encephalopathy, prothrombin time and total bilirubin level; and two distinct risk groups: low risk (28-day mortality, 10.2-39.5\%) and high risk (63.8-91.1\%). The CART model showed that patients lacking HE and with a prothrombin time $\leqslant 27.8 \mathrm{~s}$ and a bilirubin $\leqslant 5 \mathrm{mg} / \mathrm{dl}$ experienced less 28 -day mortality after ALSS therapy. For HBV-ACLF patients with HE and a PT $>27.8 \mathrm{~s}$, mortality was higher. The authors concluded that, for HBV-ACLF patients at high risk, unnecessary ALSS should be avoided [194]. The World Gastroenterology Organization (WGO) proposed classification according to the underlying liver disease: type A ACLF (patients with underlying non-cirrhotic chronic liver disease), type B ACLF (patients with previous 
compensated cirrhosis) and type C ACLF (patients with previous decompensated cirrhosis) was utilized to derive a new type-based prognostic model for HBV-related ACLF. Named the "model of ACLF prognosis based on type" or MAPT, the score, developed according to Cox proportional hazards multivariable analysis, included type of ACLF (A, B or C), age, total bilirubin, creatinine, INR and presence or absence of hepatic encephalopathy. The authors found MAPT to be superior to the CLF-C-ACLF, MELD and Child-TurcottePugh scores in predicting 90-day mortality, with an area under the receiver operating characteristic curve of 0.802 with sensitivity of $71.77 \%$, and specificity of $75.82 \%$ [195]. Recent high-quality studies have shown that TDF was superior to entecavir in HBV-ACLF (white blood cell count and HBV DNA reduction at two weeks independently predicted mortality at three months); ALSS treatment improved short-term survival and was associated with lower short-term death in patients with HBV-ACLF class 2; corticosteroid treatment did not improve transplant-free survival in patients with HBV-ACLF but, a metanalysis showed that it was effective in reducing jaundice, in-hospital mortality and ascites events; while a prospective multi-center clinical trial showed methylprednisolone therapy $(1.5 \mathrm{mg} / \mathrm{kg} / \mathrm{d}$ day $1-3 ; 1 \mathrm{mg} / \mathrm{kg} / \mathrm{d}$ day $4-5 ;$ and $0.5 \mathrm{mg} / \mathrm{kg} / \mathrm{d}$ day 6-7) increased six-month survival [196-200]. To summarize, specific mutations in HBV predispose to reactivation of the virus leading to ACLF in patients with HBV-related ACLF, which is also governed by HLA susceptibility and virus genotype in certain patient populations. Apart from the classical prognostic scores such as MELD and CLIF scores, newer prognostic tools like AARC, COSSH, ABIC, P5, MAPT and TACIA scores allow the clinician to identify patients who would benefit from early liver transplantation. Furthermore, the ALSS-prognosis model and the CART model help in identifying patients who would fail extracorporeal liver support therapy, in whom early liver transplantation is warranted. Improvement in decisions for clinical management, in the form of prediction and prognostic models and tools for assessing futility and early liver transplantation for HBV-ACLF, have become an important aspect other than the standard antiviral therapy regimen in this difficult to manage group of patients. Further clinically oriented studies and improved understanding of the virus biology and novel modifiable host factors will help the clinician in improving patient care for HBV-ACLF through an algorithmic approach that may become standard of care in the future.

\section{Conclusions}

Our understanding of the structure, biology, viral and immunopathogenesis in chronic HBV-related hepatitis has come a long way. Nonetheless, knowledge gaps still persist that currently limit our therapies toward a complete cure from this globally burdening disease. With the advent of new technologies and better tools such as next-generation sequencing, genome-wide association studies, single-cell RNA sequencing, gene editing and rigorous and well-coordinated collaborative clinical trials, we now understand viral and host-related factors in disease development and progression better than before. Novel modalities of treatments, such as viral RNA interference molecules, capsid assembly blockers, immune checkpoint inhibitors, HBsAg and cccDNA generation blocking molecules and innate immune system modulators, are in the pipeline and will eventually help us improve HBV-related patient outcomes.

\section{Additional Information \\ Disclosures}

Conflicts of interest: In compliance with the ICMJE uniform disclosure form, all authors declare the following: Payment/services info: All authors have declared that no financial support was received from any organization for the submitted work. Financial relationships: All authors have declared that they have no financial relationships at present or within the previous three years with any organizations that might have an interest in the submitted work. Other relationships: All authors have declared that there are no other relationships or activities that could appear to have influenced the submitted work.

\section{References}

1. Fricker ZP, Reddy KR: When (and when not) to treat patients with HBV infection. Clin Gastroenterol Hepatol. 2019, 17:2644-7. 10.1016/j.cgh.2019.05.039

2. Madihi S, Syed H, Lazar F, Zyad A, Benani A: A systematic review of the current hepatitis B viral infection and hepatocellular carcinoma situation in Mediterranean countries. Biomed Res Int. 2020, 2020:7027169. 10.1155/2020/7027169

3. Fonseca MA, Ling IZ, Al-Siyabi O, Co-Tanko V, Chan E, Lim SG: The efficacy of hepatitis B treatments in achieving HBsAg seroclearance: a systematic review and meta-analysis. J Viral Hepat. 2020, 27:650-62. 10.1111/jvh.13283

4. Loglio A, Lampertico P: How durable is functional cure (hepatitis B surface antigen loss) in patients with chronic hepatitis B treated with current antivirals?. Hepatol Commun. 2020, 4:5-7. 10.1002/hep4.1476

5. Leoni MC, Ustianowski A, Farooq H, Arends JE: HIV, HCV and HBV: a review of parallels and differences . Infect Dis Ther. 2018, 7:407-19. 10.1007/s40121-018-0210-5

6. Lee HM, Banini BA: Updates on chronic HBV: current challenges and future goals . Curr Treat Options Gastroenterol. 2019, 17:271-91. 10.1007/s11938-019-00236-3

7. Glebe D, Goldmann N, Lauber C, Seitz S: HBV evolution and genetic variability: impact on prevention, treatment and development of antivirals. Antiviral Res. 2021, 186:104973. 10.1016/j.antiviral.2020.104973

8. Glebe D, König A: Molecular virology of hepatitis B virus and targets for antiviral intervention . Intervirology. 2014, 57:134-40. 10.1159/000360946

9. You CR, Lee SW, Jang JW, Yoon SK: Update on hepatitis B virus infection. World J Gastroenterol. 2014, 20:13293-305. 10.3748/wjg.v20.i37.13293 
10. Dandri M, Petersen J: Latest developments in the treatment of hepatitis B . Minerva Gastroenterol Dietol. 2016, 62:88-102.

11. Tripathi N, Mousa OY: Hepatitis B 2020. StatPearls, Treasure Island; 2020.

12. Liang TJ: Hepatitis B: the virus and disease. Hepatology. 2009, 49:S13-21. 10.1002/hep.22881

13. König A, Than TT, Todt D, Yoon SK, Steinmann J, Steinmann E, Windisch MP: High tolerance of hepatitis B virus to thermal disinfection. J Hepatol. 2019, 71:1249-51. 10.1016/j.jhep.2019.08.022

14. Spyrou E, Smith CI, Ghany MG: Hepatitis B: current status of therapy and future therapies . Gastroenterol Clin North Am. 2020, 49:215-38. 10.1016/j.gtc.2020.01.003

15. McNaughton AL, D'Arienzo V, Ansari MA, et al.: Insights from deep sequencing of the HBV genome-unique, tiny, and misunderstood. Gastroenterology. 2019, 156:384-99. 10.1053/j.gastro.2018.07.058

16. Xia Y, Carpentier A, Cheng X, et al.: Human stem cell-derived hepatocytes as a model for hepatitis B virus infection, spreading and virus-host interactions. J Hepatol. 2017, 66:494-503. 10.1016/j.jhep.2016.10.009

17. Wang J, Qu B, Zhang F, Zhang C, Deng W, Dao Thi VL, Xia Y: Stem cell-derived hepatocyte-like cells as model for viral hepatitis research. Stem Cells Int. 2019, 2019:9605252. 10.1155/2019/9605252

18. Iwamoto M, Saso W, Sugiyama R, et al.: Epidermal growth factor receptor is a host-entry cofactor triggering hepatitis B virus internalization. Proc Natl Acad Sci U S A. 2019, 116:8487-92. 10.1073/pnas.1811064116

19. Hu Q, Zhang F, Duan L, et al.: E-cadherin plays a role in hepatitis B virus entry through affecting glycosylated sodium-taurocholate cotransporting polypeptide distribution. Front Cell Infect Microbiol. 2020, 10:74. 10.3389/fcimb.2020.00074

20. Macovei A, Petrareanu C, Lazar C, Florian P, Branza-Nichita N: Regulation of hepatitis B virus infection by Rab5, Rab7, and the endolysosomal compartment. J Virol. 2013, 87:6415-27. 10.1128/JVI.00393-13

21. Fukano K, Tsukuda S, Oshima M, et al.: Troglitazone impedes the oligomerization of sodium taurocholate cotransporting polypeptide and entry of hepatitis B virus into hepatocytes. Front Microbiol. 2018, 9:3257. 10.3389/fmicb.2018.03257

22. Kuipery A, Gehring AJ, Isogawa M: Mechanisms of HBV immune evasion. Antiviral Res. 2020, 179:104816. 10.1016/j.antiviral.2020.104816

23. Herrscher C, Pastor F, Burlaud-Gaillard J, et al.: Hepatitis B virus entry into HepG2-NTCP cells requires clathrin-mediated endocytosis. Cell Microbiol. 2020, 22:e13205. 10.1111/cmi.13205

24. Delgado CL, Núñez E, Yélamos B, Gómez-Gutiérrez J, Peterson DL, Gavilanes F: Study of the putative fusion regions of the preS domain of hepatitis B virus. Biochim Biophys Acta. 2015, 1848:895-906. 10.1016/j.bbamem.2014.12.020

25. White JM, Whittaker GR: Fusion of enveloped viruses in endosomes. Traffic. 2016, 17:593-614. 10.1111/tra.12389

26. Tu T, Urban S: Virus entry and its inhibition to prevent and treat hepatitis B and hepatitis D virus infections . Curr Opin Virol. 2018, 30:68-79. 10.1016/j.coviro.2018.04.004

27. Herrscher C, Roingeard P, Blanchard E: Hepatitis B virus entry into cells . Cells. 2020, 9:10.3390/cells9061486

28. Jiang B, Wu Q, Kuhnhenn L, et al.: Formation of semi-enveloped particles as a unique feature of a hepatitis B virus PreS1 deletion mutant. Aliment Pharmacol Ther. 2019, 50:940-54. 10.1111/apt.15381

29. Patel N, White SJ, Thompson RF, et al.: HBV RNA pre-genome encodes specific motifs that mediate interactions with the viral core protein that promote nucleocapsid assembly. Nat Microbiol. 2017, 2:17098. 10.1038/nmicrobiol.2017.98

30. York A: Viral infection: packing to leave. Nat Rev Microbiol. 2017, 15:450-1. 10.1038/nrmicro.2017.81

31. Zhao Q, Hu Z, Cheng J, et al.: Hepatitis B virus core protein dephosphorylation occurs during pregenomic RNA encapsidation. J Virol. 2018, 92:10.1128/JVI.02139-17

32. Jiang B, Hildt E: Intracellular trafficking of HBV particles. Cells. 2020, 9:10.3390/cells 9092023

33. Osseman Q, Gallucci L, Au S, et al.: The chaperone dynein LL1 mediates cytoplasmic transport of empty and mature hepatitis B virus capsids. J Hepatol. 2018, 68:441-8. 10.1016/j.jhep.2017.10.032

34. Zlotnick A, Venkatakrishnan B, Tan Z, Lewellyn E, Turner W, Francis S: Core protein: a pleiotropic keystone in the HBV lifecycle. Antiviral Res. 2015, 121:82-93. 10.1016/j.antiviral.2015.06.020

35. Ning X, Luckenbaugh L, Liu K, Bruss V, Sureau C, Hu J: Common and distinct capsid and surface protein requirements for secretion of complete and genome-free hepatitis B virions. J Virol. 2018, 92:10.1128/JVI.00272-18

36. Wei L, Ploss A: Core components of DNA lagging strand synthesis machinery are essential for hepatitis B virus cccDNA formation. Nat Microbiol. 2020, 5:715-26. 10.1038/s41564-020-0678-0

37. Sun S, Nakashima K, Ito M, et al.: Involvement of PUF60 in transcriptional and post-transcriptional regulation of hepatitis B virus pregenomic RNA expression. Sci Rep. 2017, 7:12874. 10.1038/s41598-01712497-y

38. Liu Y, Nie H, Mao R, et al.: Interferon-inducible ribonuclease ISG20 inhibits hepatitis B virus replication through directly binding to the epsilon stem-loop structure of viral RNA. PLoS Pathog. 2017, 13:e1006296. 10.1371/journal.ppat.1006296

39. Deng L, Gan X, Ito M, et al.: Peroxiredoxin 1, a novel HBx-interacting protein, interacts with exosome component 5 and negatively regulates hepatitis B virus (HBV) propagation through degradation of HBV RNA. J Virol. 2019, 93:10.1128/JVI.02203-18

40. Yao Y, Yang B, Cao H, et al.: RBM24 stabilizes hepatitis B virus pregenomic RNA but inhibits core protein translation by targeting the terminal redundancy sequence. Emerg Microbes Infect. 2018, 7:86. 10.1038/s41426-018-0091-4

41. Caballero A, Tabernero D, Buti M, Rodriguez-Frias F: Hepatitis B virus: the challenge of an ancient virus with multiple faces and a remarkable replication strategy. Antiviral Res. 2018, 158:34-44. 10.1016/j.antiviral.2018.07.019

42. Osseman Q, Kann M: Intracytoplasmic transport of hepatitis B virus capsids . Methods Mol Biol. 2017, 1540:37-51. 10.1007/978-1-4939-6700-1_4

43. Blondot ML, Bruss V, Kann M: Intracellular transport and egress of hepatitis B virus . J Hepatol. 2016, 64:S4959. 10.1016/j.jhep.2016.02.008 
44. Liu K, Luckenbaugh L, Ning X, Xi J, Hu J: Multiple roles of core protein linker in hepatitis B virus replication. PLoS Pathog. 2018, 14:e1007085. 10.1371/journal.ppat.1007085

45. Bai L, Zhang X, Kozlowski M, et al.: Extracellular hepatitis B virus RNAs are heterogeneous in length and circulate as capsid-antibody complexes in addition to virions in chronic hepatitis B patients. J Virol. 2018, 92:10.1128/JVI.00798-18

46. Pastor F, Herrscher C, Patient R, et al.: Direct interaction between the hepatitis B virus core and envelope proteins analyzed in a cellular context. Sci Rep. 2019, 9:16178. 10.1038/s41598-019-52824-z

47. Tsukuda S, Watashi K: Hepatitis B virus biology and life cycle . Antiviral Res. 2020, 182:104925. 10.1016/j.antiviral.2020.104925

48. Saeed U, Kim J, Piracha ZZ, et al.: Parvulin 14 and Parvulin 17 Bind to HBx and cccDNA and upregulate hepatitis B virus replication from cccDNA to virion in an HBx-dependent manner. J Virol. 2019, 93:10.1128/JVI.01840-18

49. Luo J, Xi J, Gao L, Hu J: Role of Hepatitis B virus capsid phosphorylation in nucleocapsid disassembly and covalently closed circular DNA formation. PLoS Pathog. 2020, 16:e1008459. 10.1371/journal.ppat.1008459

50. Slagle BL, Bouchard MJ: Hepatitis B virus X and regulation of viral gene expression . Cold Spring Harb Perspect Med. 2016, 6:a021402. 10.1101/cshperspect.a021402

51. Sekiba K, Otsuka M, Ohno M, et al.: Inhibition of HBV transcription from cccDNA with nitazoxanide by targeting the HBx-DDB1 Interaction. Cell Mol Gastroenterol Hepatol. 2019, 7:297-312.

10.1016/j.jcmgh.2018.10.010

52. Huang Q, Zhou B, Cai D, et al.: Rapid turnover of hepatitis B virus covalently closed circular DNA indicated by monitoring emergence and reversion of signature-mutation in treated chronic hepatitis B patients. Hepatology. 2021, 73:41-52. 10.1002/hep.31240

53. Luo J, Luckenbaugh L, Hu H, Yan Z, Gao L, Hu J: Involvement of host ATR-CHK1 pathway in hepatitis B Virus covalently closed circular DNA formation. mBio. 2020, 11:10.1128/mBio.03423-19

54. Schreiner S, Nassal M: A role for the host DNA damage response in hepatitis B virus cccDNA formation-and beyond?. Viruses. 2017, 9:10.3390/v9050125

55. Tang L, Sheraz M, McGrane M, Chang J, Guo JT: DNA Polymerase alpha is essential for intracellular amplification of hepatitis B virus covalently closed circular DNA. PLoS Pathog. 2019, 15:e1007742. 10.1371/journal.ppat.1007742

56. Tu T, Budzinska MA, Shackel NA, Urban S: HBV DNA integration: molecular mechanisms and clinical implications. Viruses. 2017, 9:10.3390/v9040075

57. Tang LS, Covert E, Wilson E, Kottilil S: Chronic hepatitis B infection: a review . JAMA. 2018, 319:1802-13. 10.1001/jama.2018.3795

58. Xia Y, Schlapschy M, Morath V, et al.: PASylated interferon $\alpha$ efficiently suppresses hepatitis B virus and induces anti-HBs seroconversion in HBV-transgenic mice. Antiviral Res. 2019, 161:134-43. 10.1016/j.antiviral.2018.11.003

59. Mitra B, Thapa RJ, Guo H, Block TM: Host functions used by hepatitis B virus to complete its life cycle: implications for developing host-targeting agents to treat chronic hepatitis B. Antiviral Res. 2018, 158:18598. 10.1016/j.antiviral.2018.08.014

60. Li H, Yan L, Shi Y, Lv D, Shang J, Bai L, Tang H: Hepatitis B virus infection: overview. Adv Exp Med Biol. 2020, 1179:1-16. 10.1007/978-981-13-9151-4_1

61. Tseng TC, Huang LR: Immunopathogenesis of hepatitis B virus. J Infect Dis. 2017, 216:S765-70. 10.1093/infdis/jix356

62. Zhou H, Gewaily D, Ahn SH, et al.: Sequence analysis and functional characterization of full-length hepatitis B virus genomes from Korean cirrhotic patients with or without liver cancer. Virus Res. 2017, 235:86-95. 10.1016/j.virusres.2017.03.021

63. Norder H, Twagirumugabe T, Said J, Tian Y, Tang KW, Lindh M: High frequency of either altered pre-core start codon or weakened kozak sequence in the core promoter region in hepatitis B virus A1 strains from Rwanda. Genes (Basel). 2019, 10:10.3390/genes10030182

64. Colagrossi L, Hermans LE, Salpini R, et al.: Immune-escape mutations and stop-codons in HBsAg develop in a large proportion of patients with chronic HBV infection exposed to anti-HBV drugs in Europe. BMC Infect Dis. 2018, 18:251. 10.1186/s12879-018-3161-2

65. Hayes CN, Zhang Y, Makokha GN, Hasan MZ, Omokoko MD, Chayama K: Early events in hepatitis B virus infection: from the cell surface to the nucleus. J Gastroenterol Hepatol. 2016, 31:302-9. 10.1111/jgh.13175

66. Lamontagne RJ, Bagga S, Bouchard MJ: Hepatitis B virus molecular biology and pathogenesis. Hepatoma Res. 2016, 2:163-86. 10.20517/2394-5079.2016.05

67. Hayer J, Jadeau F, Deléage G, Kay A, Zoulim F, Combet C: HBVdb: a knowledge database for hepatitis B virus. Nucleic Acids Res. 2013, 41:D566-70. 10.1093/nar/gks1022

68. Shin EC, Sung PS, Park SH: Immune responses and immunopathology in acute and chronic viral hepatitis . Nat Rev Immunol. 2016, 16:509-23. 10.1038/nri.2016.69

69. Sun HH, Zhou DF, Zhou JY: The role of DCs in the immunopathogenesis of chronic HBV infection and the methods of inducing DCs maturation. J Med Virol. 2016, 88:13-20. 10.1002/jmv.24306

70. Golsaz-Shirazi F, Shokri F: Hepatitis B immunopathogenesis and immunotherapy . Immunotherapy. 2016, 8:461-77. 10.2217/imt.16.3

71. Brempelis KJ, Crispe IN: Infiltrating monocytes in liver injury and repair. Clin Transl Immunology. 2016, 5:e113. 10.1038/cti.2016.62

72. Schuch A, Zecher BF, Müller PA, et al.: NK-cell responses are biased towards CD16-mediated effector functions in chronic hepatitis B virus infection. J Hepatol. 2019, 70:351-60. 10.1016/j.jhep.2018.10.006

73. Peppa D, Gill US, Reynolds G, et al.: Up-regulation of a death receptor renders antiviral T cells susceptible to NK cell-mediated deletion. J Exp Med. 2013, 210:99-114. 10.1084/jem.20121172

74. Zheng Q, Zhu YY, Chen J, et al.: Activated natural killer cells accelerate liver damage in patients with chronic hepatitis B virus infection. Clin Exp Immunol. 2015, 180:499-508. 10.1111/cei.12597

75. Wang X, Dong Q, Li Q, et al.: Dysregulated response of follicular helper T cells to hepatitis B surface antigen promotes HBV persistence in mice and associates with outcomes of patients. Gastroenterology. 2018, 
154:2222-36. 10.1053/j.gastro.2018.03.021

76. Dietze KK, Schimmer S, Kretzmer F, et al.: Characterization of the Treg response in the hepatitis B virus hydrodynamic injection mouse model. PLoS One. 2016, 11:e0151717. 10.1371/journal.pone.0151717

77. Zeng Z, Li L, Chen Y, Wei H, Sun R, Tian Z: Interferon- $\gamma$ facilitates hepatic antiviral $\mathrm{T}$ cell retention for the maintenance of liver-induced systemic tolerance. J Exp Med. 2016, 213:1079-93. 10.1084/jem.20151218

78. Yang F, Yu X, Zhou C, et al.: Hepatitis B e antigen induces the expansion of monocytic myeloid-derived suppressor cells to dampen T-cell function in chronic hepatitis B virus infection. PLoS Pathog. 2019, 15:e1007690. 10.1371/journal.ppat.1007690

79. Bertoletti A, Ferrari C: Adaptive immunity in HBV infection. J Hepatol. 2016, 64:S71-83. 10.1016/j.jhep.2016.01.026

80. Xu Y, Wang Z, Du X, et al.: Tim-3 blockade promotes iNKT cell function to inhibit HBV replication. J Cell Mol Med. 2018, 22:3192-201.10.1111/jcmm.13600

81. Pal S, Nandi M, Dey D, et al.: Myeloid-derived suppressor cells induce regulatory T cells in chronically HBV infected patients with high levels of hepatitis B surface antigen and persist after antiviral therapy. Aliment Pharmacol Ther. 2019, 49:1346-59. 10.1111/apt.15226

82. Chang KM, Liu M: Chronic hepatitis B: immune pathogenesis and emerging immunotherapeutics . Curr Opin Pharmacol. 2016, 30:93-105. 10.1016/j.coph.2016.07.013

83. Hou Z, Zhang J, Han Q, et al.: Hepatitis B virus inhibits intrinsic RIG-I and RIG-G immune signaling via inducing miR146a. Sci Rep. 2016, 6:26150. 10.1038/srep26150

84. Montalbano R, Honrath B, Wissniowski TT, et al.: Exogenous hepatitis B virus envelope proteins induce endoplasmic reticulum stress: involvement of cannabinoid axis in liver cancer cells. Oncotarget. 2016, 7:20312-23. 10.18632/oncotarget.7950

85. Choi YM, Lee SY, Kim BJ: Naturally occurring hepatitis B virus mutations leading to endoplasmic reticulum stress and their contribution to the progression of hepatocellular carcinoma. Int J Mol Sci. 2019, 20:10.3390/ijms20030597

86. He C, Qiu Y, Han P, et al.: ER stress regulating protein phosphatase 2A-B56y, targeted by hepatitis B virus X protein, induces cell cycle arrest and apoptosis of hepatocytes. Cell Death Dis. 2018, 9:762. 10.1038/s41419018-0787-3

87. Tu T, Bühler S, Bartenschlager R: Chronic viral hepatitis and its association with liver cancer . Biol Chem. 2017, 398:817-37. 10.1515/hsz-2017-0118

88. Deng M, Hou J, Hu J, et al.: Hepatitis B virus mRNAs functionally sequester let-7a and enhance hepatocellular carcinoma. Cancer Lett. 2016, 383:62-72. 10.1016/j.canlet.2016.09.028

89. Lamontagne J, Steel LF, Bouchard MJ: Hepatitis B virus and microRNAs: Complex interactions affecting hepatitis B virus replication and hepatitis B virus-associated diseases. World J Gastroenterol. 2015, 21:737599. 10.3748/wjg.v21.i24.7375

90. Otsuka M, Kishikawa T, Yoshikawa T, et al.: MicroRNAs and liver disease . J Hum Genet. 2017, 62:75-80. 10.1038/jhg.2016.53

91. Sunbul M: Hepatitis B virus genotypes: global distribution and clinical importance . World J Gastroenterol. 2014, 20:5427-34. 10.3748/wjg.v20.i18.5427

92. Liu CJ, Kao JH: Global perspective on the natural history of chronic hepatitis B: role of hepatitis B virus genotypes A to J. Semin Liver Dis. 2013, 33:97-102. 10.1055/s-0033-1345716

93. Chen CJ, Yang HI: Natural history of chronic hepatitis B REVEALed. J Gastroenterol Hepatol. 2011, 26:62838. 10.1111/j.1440-1746.2011.06695.x

94. Lin CL, Kao JH: Hepatitis B virus genotypes and variants . Cold Spring Harb Perspect Med. 2015, 5:a021436. 10.1101/cshperspect.a021436

95. Madan K, Batra Y, Sreenivas V, et al.: HBV genotypes in India: do they influence disease severity? . Hepatol Res. 2009, 39:157-63. 10.1111/j.1872-034X.2008.00417.x

96. Kramvis A: The clinical implications of hepatitis B virus genotypes and HBeAg in pediatrics . Rev Med Virol. 2016, 26:285-303. 10.1002/rmv.1885

97. Chauhan R, Singh AK, Rooge S, Varshney A, Kumar M, Sarin SK: Analysis of hepatitis B virus genotype changes in patients with chronic hepatitis B infection on tenofovir therapy. J Med Virol. 2016, 88:1364-75. 10.1002/jmv.24489

98. Rodríguez M, Buti M, Esteban R, Lens S, Prieto M, Suárez E, García-Samaniego J: Consensus document of the Spanish association for study of the liver on the treatment of hepatitis B virus infection. Gastroenterol Hepatol. 2020, 43:559-87. 10.1016/j.gastrohep.2020.03.011

99. Yuen MF, Ahn SH, Chen DS, et al.: Chronic hepatitis B virus infection: disease revisit and management Recommendations. J Clin Gastroenterol. 2016, 50:286-94. 10.1097/MCG.0000000000000478

100. Kim SW, Yoon JS, Lee M, Cho Y: Toward a complete cure for chronic hepatitis B: novel therapeutic targets for hepatitis B virus. Clin Mol Hepatol. 2021, 69:391-9. 10.3350/cmh.2021.0093

101. Peters MG: Hepatitis B virus infection: what is current and new . Top Antivir Med. 2019, 26:112-6.

102. Wendon, J, Cordoba J, Dhawan A, et al.: EASL Clinical Practical Guidelines on the management of acute (fulminant) liver failure. J Hepatol. 2017, 66:1047-81. 10.1016/j.jhep.2016.12.003

103. Coffin CS, Zhou K, Terrault NA: New and old biomarkers for diagnosis and management of chronic hepatitis B virus infection. Gastroenterology. 2019, 156:355-368.e3. 10.1053/j.gastro.2018.11.037

104. Likhitsup A, Lok AS: Understanding the natural history of hepatitis B virus infection and the new definitions of cure and the endpoints of clinical trials. Clin Liver Dis. 2019, 23:401-16. 10.1016/j.cld.2019.04.002

105. Raimondo G, Locarnini S, Pollicino T, Levrero M, Zoulim F, Lok AS: Update of the statements on biology and clinical impact of occult hepatitis B virus infection. J Hepatol. 2019, 71:397-408. 10.1016/j.jhep.2019.03.034

106. Nicolini LA, Orsi A, Tatarelli P, Viscoli C, Icardi G, Sticchi L: A global view to HBV chronic infection: evolving strategies for diagnosis, treatment and prevention in immunocompetent individuals. Int J Environ Res Public Health. 2019, 16:10.3390/ijerph16183307

107. Tada T, Kumada T, Toyoda H, et al.: HBcrAg predicts hepatocellular carcinoma development: An analysis using time-dependent receiver operating characteristics. J Hepatol. 2016, 65:48-56. 10.1016/j.jhep.2016.03.013 
108. Jung KS, Park JY, Chon YE, et al.: Clinical outcomes and predictors for relapse after cessation of oral antiviral treatment in chronic hepatitis B patients. J Gastroenterol. 2016, 51:830-9. 10.1007/s00535-0151153-1

109. Caviglia GP, Abate ML, Noviello D, et al.: Hepatitis B core-related antigen kinetics in chronic hepatitis B virus genotype $\mathrm{D}$-infected patients treated with nucleos(t)ide analogues or pegylated-interferon- $\alpha$. Hepatol Res. 2017, 47:747-54. 10.1111/hepr.12811

110. Wang J, Yu Y, Li G, et al.: Relationship between serum HBV-RNA levels and intrahepatic viral as well as histologic activity markers in entecavir-treated patients. J Hepatol. 2017, 10.1016/j.jhep.2017.08.021

111. European Association for the Study of the Liver: EASL 2017 Clinical Practice Guidelines on the management of hepatitis B virus infection. J Hepatol. 2017, 67:370-98. 10.1016/j.jhep.2017.03.021

112. Terrault NA, Lok AS, McMahon BJ, et al.: Update on prevention, diagnosis, and treatment of chronic hepatitis B: AASLD 2018 hepatitis B guidance. Hepatology. 2018, 67:1560-99. 10.1002/hep.29800

113. Halgand B, Desterke C, Rivière L, et al.: Hepatitis B virus pregenomic RNA in hepatocellular carcinoma: a nosological and prognostic determinant. Hepatology. 2018, 67:86-96. 10.1002/hep.29463

114. Wang J, Yu Y, Li G, et al.: Natural history of serum HBV-RNA in chronic HBV infection . J Viral Hepat. 2018, 25:1038-47. 10.1111/jvh.12908

115. van Campenhout MJ, van Bömmel F, Pfefferkorn M, et al.: Serum hepatitis B virus RNA predicts response to peginterferon treatment in HBeAg-positive chronic hepatitis B. J Viral Hepat. 2020, 27:610-9. 10.1111/jvh.13272

116. Fan R, Zhou B, Xu M, et al.: Association between negative results from tests for HBV DNA and RNA and durability of response after discontinuation of nucles(t)ide analogue therapy. Clin Gastroenterol Hepatol. 2020, 18:719-727.e7. 10.1016/j.cgh.2019.07.046

117. Wang W, Tian SL, Wang H, Shao CC, Wang YZ, Li YL: Association of hepatitis B virus DNA level and followup interval with hepatocellular carcinoma recurrence. JAMA Netw Open. 2020, 3:e203707. 10.1001/jamanetworkopen.2020.3707

118. Rybicka M, Bielawski KP: Recent advances in understanding, diagnosing, and treating hepatitis B virus infection. Microorganisms. 2020, 8:10.3390/microorganisms8091416

119. Wei R, Wang J, Wang X, et al.: Clinical prediction of HBV and HCV related hepatic fibrosis using machine learning. EBioMedicine. 2018, 35:124-32. 10.1016/j.ebiom.2018.07.041

120. Tian X, Chong Y, Huang Y, et al.: Using machine learning algorithms to predict hepatitis B surface antigen seroclearance. Comput Math Methods Med. 2019, 2019:6915850. 10.1155/2019/6915850

121. Remita MA, Halioui A, Malick Diouara AA, Daigle B, Kiani G, Diallo AB: A machine learning approach for viral genome classification. BMC Bioinformatics. 2017, 18:208. 10.1186/s12859-017-1602-3

122. Mueller-Breckenridge AJ, Garcia-Alcalde F, Wildum S, et al.: Machine-learning based patient classification using Hepatitis B virus full-length genome quasispecies from Asian and European cohorts. Sci Rep. 2019, 9:18892. 10.1038/s41598-019-55445-8

123. Chen QF, Xia JG, Li W, Shen LJ, Huang T, Wu P: Examining the key genes and pathways in hepatocellular carcinoma development from hepatitis B virus-positive cirrhosis. Mol Med Rep. 2018, 18:4940-50. 10.3892/mmr.2018.9494

124. Nguyen MH, Wong G, Gane E, Kao JH, Dusheiko G: Hepatitis B virus: advances in prevention, diagnosis, and therapy. Clin Microbiol Rev. 2020, 33: 10.1128/CMR.00046-19

125. Jeng WJ, Lok AS: Should treatment indications for chronic hepatitis B be expanded? . Clin Gastroenterol Hepatol. 2021, 19:2006-14. 10.1016/j.cgh.2020.04.091

126. Cornberg M, Lok AS, Terrault NA, Zoulim F: Guidance for design and endpoints of clinical trials in chronic hepatitis B - report from the 2019 EASL-AASLD HBV Treatment Endpoints Conferenceł. J Hepatol. 2020, 72:539-57. 10.1016/j.jhep.2019.11.003

127. Alawad AS, Auh S, Suarez D, Ghany MG: Durability of spontaneous and treatment-related loss of hepatitis B S antigen. Clin Gastroenterol Hepatol. 2020, 18:700-9. 10.1016/j.cgh.2019.07.018

128. Huang DQ, Lim SG: Hepatitis B: who to treat? A critical review of international guidelines . Liver Int. 2020, 40:5-14. 10.1111/liv.14365

129. Fourati S, Pawlotsky JM: Recent advances in understanding and diagnosing hepatitis B virus infection . F1000Res. 2016, 5:10.12688/f1000research.8983.1

130. Smolders EJ, Burger DM, Feld JJ, Kiser JJ: Review article: clinical pharmacology of current and investigational hepatitis B virus therapies. Aliment Pharmacol Ther. 2020, 51:231-43. 10.1111/apt.15581

131. Pileggi C, Papadopoli R, Bianco A, Pavia M: Hepatitis B vaccine and the need for a booster dose after primary vaccination. Vaccine. 2017, 35:6302-7. 10.1016/j.vaccine.2017.09.076

132. Hassanein TI: Hepatitis B virus update. Clin Liver Dis. 2019, 23 :xiii-xiv. 10.1016/j.cld.2019.05.002

133. Lai MW, Chang MH: Updates in the management of hepatitis B in children . Expert Rev Gastroenterol Hepatol. 2019, 13:1065-76. 10.1080/17474124.2019.1686975

134. Zhao H, Zhou X, Zhou YH: Hepatitis B vaccine development and implementation. Hum Vaccin Immunother. 2020, 16:1533-44. 10.1080/21645515.2020.1732166

135. Lopatin U: Drugs in the pipeline for HBV . Clin Liver Dis. 2019, 23:535-55. 10.1016/j.cld.2019.04.006

136. Do A, Reau NS: Chronic viral hepatitis: current management and future directions . Hepatol Commun. 2020, 4:329-41. 10.1002/hep4.1480

137. Fanning GC, Zoulim F, Hou J, Bertoletti A: Therapeutic strategies for hepatitis B virus infection: towards a cure. Nat Rev Drug Discov. 2019, 18:827-44. 10.1038/s41573-019-0037-0

138. Berg T, Simon KG, Mauss S, et al.: Long-term response after stopping tenofovir disoproxil fumarate in noncirrhotic HBeAg-negative patients - FINITE study. J Hepatol. 2017, 67:918-24. 10.1016/j.jhep.2017.07.012

139. Yim HJ, Kim JH, Park JY, et al.: Comparison of clinical practice guidelines for the management of chronic hepatitis B: when to start, when to change, and when to stop. Clin Mol Hepatol. 2020, 26:411-29. 10.3350/cmh.2020.0049

140. Gill US, Kennedy PT: The impact of currently licensed therapies on viral and immune responses in chronic hepatitis B: considerations for future novel therapeutics. J Viral Hepat. 2019, 26:4-15. 10.1111/jvh.13040

141. Wilkins T, Sams R, Carpenter M: Hepatitis B: screening, prevention, diagnosis, and treatment. Am Fam 
Physician. 2019, 99:314-23.

142. Tillmann HL, Samuel G: Current state-of-the-art pharmacotherapy for the management of hepatitis B infection. Expert Opin Pharmacother. 2019, 20:873-85. 10.1080/14656566.2019.1583744

143. Xia Y, Guo H: Hepatitis B virus cccDNA: formation, regulation and therapeutic potential . Antiviral Res. 2020, 180:104824. 10.1016/j.antiviral.2020.104824

144. Suk-Fong Lok A: Hepatitis B treatment: what we know now and what remains to be researched . Hepatol Commun. 2019, 3:8-19. 10.1002/hep4.1281

145. Myint A, Tong MJ, Beaven SW: Reactivation of hepatitis B virus: a review of clinical guidelines . Clin Liver Dis (Hoboken). 2020, 15:162-7. 10.1002/cld.883

146. Husa P: Current view on hepatitis B diagnosis and therapy. Vnitr Lek. 2019, 65:546-51. 10.36290/vnl.2019.095

147. Revill PA, Chisari FV, Block JM, et al.: A global scientific strategy to cure hepatitis B . Lancet Gastroenterol Hepatol. 2019, 4:545-58. 10.1016/S2468-1253(19)30119-0

148. Lin CL, Yang HC, Kao JH: Hepatitis B virus: new therapeutic perspectives . Liver Int. 2016, 36:85-92. 10.1111/liv.13003

149. Lin CL, Kao JH: Review article: novel therapies for hepatitis B virus cure - advances and perspectives . Aliment Pharmacol Ther. 2016, 44:213-22. 10.1111/apt.13694

150. Schinazi RF, Ehteshami M, Bassit L, Asselah T: Towards HBV curative therapies. Liver Int. 2018, 38:102-14. 10.1111/liv.13656

151. Ohno M, Otsuka M, Kishikawa T, Yoshikawa T, Takata A, Koike K: Novel therapeutic approaches for hepatitis B virus covalently closed circular DNA. World J Gastroenterol. 2015, 21:7084-8. 10.3748/wjg.v21.i23.7084

152. Peng C, Lu M, Yang D: CRISPR/Cas9-based tools for targeted genome editing and replication control of HBV. Virol Sin. 2015, 30:317-25. 10.1007/s12250-015-3660-x

153. Moyo B, Bloom K, Scott T, Ely A, Arbuthnot P: Advances with using CRISPR/Cas-mediated gene editing to treat infections with hepatitis B virus and hepatitis C virus. Virus Res. 2018, 244:311-20. 10.1016/j.virusres.2017.01.003

154. Shih C, Chou SF, Yang CC, Huang JY, Choijilsuren G, Jhou RS: Control and eradication strategies of hepatitis B virus. Trends Microbiol. 2016, 24:739-49. 10.1016/j.tim.2016.05.006

155. Yuen MF, Gane EJ, Kim DJ, et al.: Antiviral activity, safety, and pharmacokinetics of capsid assembly modulator NVR 3-778 in patients with chronic HBV infection. Gastroenterology. 2019, 156:1392-1403. 10.1053/j.gastro.2018.12.023

156. Alonso S, Guerra AR, Carreira L, Ferrer JÁ, Gutiérrez ML, Fernandez-Rodriguez CM: Upcoming pharmacological developments in chronic hepatitis B: can we glimpse a cure on the horizon? BMC Gastroenterol. 2017, 17:168. 10.1186/s12876-017-0726-2

157. Gane EJ: Future anti-HBV strategies. Liver Int. 2017, 37:40-4. 10.1111/liv.13304

158. Cox AL, El-Sayed MH, Kao JH, Lazarus JV, Lemoine M, Lok AS, Zoulim F: Progress towards elimination goals for viral hepatitis. Nat Rev Gastroenterol Hepatol. 2020, 17:533-42. 10.1038/s41575-020-0332-6

159. van den Berg F, Limani SW, Mnyandu N, Maepa MB, Ely A, Arbuthnot P: Advances with RNAi-based therapy for hepatitis B virus infection. Viruses. 2020, 12:10.3390/v12080851

160. Lang J, Neumann-Haefelin C, Thimme R: Immunological cure of HBV infection. Hepatol Int. 2019, 13:11324. 10.1007/s12072-018-9912-8

161. Martinez MG, Villeret F, Testoni B, Zoulim F: Can we cure hepatitis B virus with novel direct-acting antivirals?. Liver Int. 2020, 40:27-34. 10.1111/liv.14364

162. Edwards TC, Lomonosova E, Patel JA, et al.: Inhibition of hepatitis B virus replication by Nhydroxyisoquinolinediones and related polyoxygenated heterocycles. Antiviral Res. 2017, 143:205-17. 10.1016/j.antiviral.2017.04.012

163. Lee HW, Lee JS, Ahn SH: Hepatitis B virus cure: targets and future therapies . Int J Mol Sci. 2020, 22:10.3390/ijms22010213

164. Yang L, Liu F, Tong X, Hoffmann D, Zuo J, Lu M: Treatment of chronic hepatitis B virus infection using small molecule modulators of nucleocapsid assembly: recent advances and perspectives. ACS Infect Dis. 2019, 5:713-24. 10.1021/acsinfecdis.8b00337

165. Suslov A, Wieland S, Menne S: Modulators of innate immunity as novel therapeutics for treatment of chronic hepatitis B. Curr Opin Virol. 2018, 30:9-17. 10.1016/j.coviro.2018.01.008

166. Dawood A, Abdul Basit S, Jayaraj M, Gish RG: Drugs in development for hepatitis B . Drugs. 2017, 77:126380. 10.1007/s40265-017-0769-2

167. Kim WR: Emerging therapies toward a functional cure for hepatitis b virus infection . Gastroenterol Hepatol (N Y). 2018, 14:439-42.

168. Hoogeveen RC, Boonstra A: Checkpoint inhibitors and therapeutic vaccines for the treatment of chronic HBV infection. Front Immunol. 2020, 11:401. 10.3389/fimmu.2020.00401

169. Mouzannar K, Liang TJ: Hepatitis B virus - recent therapeutic advances and challenges to cure . J Hepatol. 2020, 73:694-5. 10.1016/j.jhep.2020.04.015

170. Zahn T, Akhras S, Spengler C, Murra RO, Holzhauser T, Hildt E: A new approach for therapeutic vaccination against chronic HBV infections. Vaccine. 2020, 38:3105-20. 10.1016/j.vaccine.2020.02.063

171. Whitacre DC, Peters CJ, Sureau C, et al.: Designing a therapeutic hepatitis B vaccine to circumvent immune tolerance. Hum Vaccin Immunother. 2020, 16:251-68. 10.1080/21645515.2019.1689745

172. Zoulim F, Fournier C, Habersetzer F, et al.: Safety and immunogenicity of the therapeutic vaccine TG1050 in chronic hepatitis B patients: a phase 1b placebo-controlled trial. Hum Vaccin Immunother. 2020, 16:388-99. 10.1080/21645515.2019.1651141

173. Hayakawa M, Umeyama H, Iwadate M, et al.: Development of a novel anti-hepatitis B virus agent via Sp1 . Sci Rep. 2020, 10:47. 10.1038/s41598-019-56842-9

174. Tao Y, Wu D, Zhou L, et al.: Present and future therapies for chronic hepatitis B . Adv Exp Med Biol. 2020, 1179:137-86. 10.1007/978-981-13-9151-4_6

175. Soriano V, Barreiro P, Cachay E, Kottilil S, Fernandez-Montero JV, de Mendoza C: Advances in hepatitis B 
therapeutics. Ther Adv Infect Dis. 2020, 7: 10.1177/2049936120965027

176. Alexopoulou A, Vasilieva L, Karayiannis P: New approaches to the treatment of chronic hepatitis B . J Clin Med. 2020, 9:10.3390/jcm9103187

177. Kumar R, Mehta G, Jalan R: Acute-on-chronic liver failure. Clin Med (Lond). 2020, 20:501-4. 10.7861/clinmed.2020-0631

178. O'Brien A, Karvellas CJ: Acute-on-chronic liver failure: the challenge of PREDICTing who and when . J Hepatol. 2020, 73:755-6. 10.1016/j.jhep.2020.07.029

179. Sarin SK, Choudhury A, Sharma MK, et al.: Acute-on-chronic liver failure: consensus recommendations of the Asian Pacific association for the study of the liver (APASL): an update. Hepatol Int. 2019, 13:353-90. 10.1007/s12072-019-09946-3

180. Devarbhavi H, Choudhury AK, Sharma MK, et al.: Drug-induced acute-on-chronic liver failure in asian patients. Am J Gastroenterol. 2019, 114:929-37. 10.14309/ajg.0000000000000201

181. Hu F, Bi S, Yan H, Shi Y, Sheng J: Associations between hepatitis B virus basal core promoter/pre-core region mutations and the risk of acute-on-chronic liver failure: a meta-analysis. Virol J. 2015, 12:87. 10.1186/s12985-015-0313-5

182. Tan W, Xia J, Dan Y, et al.: Genome-wide association study identifies HLA-DR variants conferring risk of HBV-related acute-on-chronic liver failure. Gut. 2018, 67:757-66. 10.1136/gutjnl-2016-313035

183. Nian X, Xu Z, Liu Y, Chen J, Li X, Xu D: Association between hepatitis B virus basal core promoter/precore region mutations and the risk of hepatitis B-related acute-on-chronic liver failure in the Chinese population: an updated meta-analysis. Hepatol Int. 2016, 10:606-15. 10.1007/s12072-016-9716-7

184. Zhao RH, Shi Y, Zhao H, Wu W, Sheng JF: Acute-on-chronic liver failure in chronic hepatitis B: an update . Expert Rev Gastroenterol Hepatol. 2018, 12:341-50. 10.1080/17474124.2018.1426459

185. Fan W, Liao W, Luo Y, You B, Yu J, Li C: Clinical prediction for outcomes of patients with acute-on-chronic liver failure associated with HBV infection: a new model establishment. Open Med (Wars). 2020, 15:714-22. 10.1515/med-2020-0207

186. Qiang L, Qin J, Sun C, et al.: A novel predictive model based on inflammatory markers to assess the prognosis of patients with HBV-related acute-on-chronic liver failure: a retrospective cohort study. BMC Gastroenterol. 2020, 20:301. 10.1186/s12876-020-01437-2

187. Fan Z, EnQiang C, Yao DL, et al.: Neutrophil-lymphocyte ratio predicts short term mortality in patients with hepatitis B virus-related acute-on-chronic liver failure treated with an artificial liver support system. PLoS One. 2017, 12:e0175332. 10.1371/journal.pone.0175332

188. Wu T, Li J, Shao L, et al.: Development of diagnostic criteria and a prognostic score for hepatitis B virusrelated acute-on-chronic liver failure. Gut. 2018, 67:2181-91. 10.1136/gutjnl-2017-314641

189. Wu D, Sun Z, Liu X, et al.: HINT: a novel prognostic model for patients with hepatitis B virus-related acuteon-chronic liver failure. Aliment Pharmacol Ther. 2018, 48:750-60. 10.1111/apt.14927

190. Chen L, Zheng J, Cai J, et al.: Predictive value of age-bilirubin-international normalized ratio-creatinine score in short-term survival of acute-on-chronic hepatitis B liver failure. Cell Physiol Biochem. 2018, 51:2484-95. 10.1159/000495904

191. Wu D, Zhang S, Xie Z, et al.: Plasminogen as a prognostic biomarker for HBV-related acute-on-chronic liver failure. J Clin Invest. 2020, 130:2069-80. 10.1172/JCI130197

192. Wang X, Sun M, Yang X, et al.: Value of liver regeneration in predicting short-term prognosis for patients with hepatitis B-related acute-on-chronic liver failure. Biomed Res Int. 2020, 2020:5062873. 10.1155/2020/5062873

193. Xie Z, Violetta L, Chen E, et al.: A prognostic model for hepatitis B acute-on-chronic liver failure patients treated using a plasma exchange-centered liver support system. J Clin Apher. 2020, 35:94-103. 10.1002/jca.21762

194. Huang K, Ji F, Xie Z, et al.: Artificial liver support system therapy in acute-on-chronic hepatitis B liver failure: classification and regression tree analysis. Sci Rep. 2019, 9:16462. 10.1038/s41598-019-53029-0

195. Mu X, Tong J, Xu X, et al.: World Gastroenterology Organisation classification and a new type-based prognostic model for hepatitis B virus-related acute-on-chronic liver failure. Clin Res Hepatol Gastroenterol. 2021, 45:101548. 10.1016/j.clinre.2020.09.009

196. Wan YM, Li YH, Xu ZY, Wu HM, Xu Y, Wu XN, Yang JH: Tenofovir versus entecavir for the treatment of acute-on-chronic liver failure due to reactivation of chronic hepatitis B with genotypes B and C. J Clin Gastroenterol. 2019, 53:e171-7. 10.1097/MCG.0000000000001038

197. Yang L, Wu T, Li J, et al.: Artificial liver treatment improves survival in patients with hepatitis B virusrelated acute-on-chronic liver failure: a case-control matched analysis. Hepatol Res. 2020, 50:656-70. 10.1111/hepr.13497

198. Huang C, Yu KK, Zheng JM, Li N: Steroid treatment in patients with acute-on-chronic liver failure precipitated by hepatitis B: a 10-year cohort study in a university hospital in East China. J Dig Dis. 2019, 20:38-44. 10.1111/1751-2980.12691

199. Gao R, Li Y, Cao Y, Zheng R, Tang L, Yang J, Lu X: Glucocorticoid versus traditional therapy for hepatitis B virus-related acute-on-chronic liver failure: a systematic review and meta-analysis. Medicine (Baltimore). 2020, 99:e20604. 10.1097/MD.0000000000020604

200. Jia L, Xue R, Zhu Y, et al.: The efficacy and safety of methylprednisolone in hepatitis B virus-related acuteon-chronic liver failure: a prospective multi-center clinical trial. BMC Med. 2020, 18:383. 10.1186/s12916020-01814-4 